\title{
Axial Compressive Performance of Steel-Reinforced Concrete Columns with Monosymmetric Cross-Shaped Steel
}

\author{
Jipeng Yu, Tianhua Zhou 1 , Yu Zhang, and Yapeng Li \\ School of Civil Engineering, Chang'an University, Xi'an, Shaanxi 710061, China \\ Correspondence should be addressed to Tianhua Zhou; zhouth@chd.edu.cn
}

Received 12 October 2020; Revised 20 December 2020; Accepted 20 January 2021; Published 10 February 2021

Academic Editor: Michael Yam

Copyright (c) 2021 Jipeng $\mathrm{Yu}$ et al. This is an open access article distributed under the Creative Commons Attribution License, which permits unrestricted use, distribution, and reproduction in any medium, provided the original work is properly cited.

\begin{abstract}
The axial compressive performance of steel-reinforced concrete columns with monosymmetric cross-shaped steel (SRCC-MCS) was investigated in this study. Tests were conducted under pure axial compression to determine the effects of cross-shaped steel eccentricity ratio, concrete strength, steel ratio, and stirrup spacing on the resulting failure mode, load-strain curves, and loaddisplacement curves. The results indicated that increasing the cross-shaped steel eccentricity ratio reduced the axial capacity and ductility, increasing the concrete strength markedly enhanced the axial capacity but reduced the ductility, and increasing the steel ratio and reducing the stirrup spacing increased the axial capacity and ductility. Two calculation methods for determining the axial capacity of an SRCC-MCS under axial compression were proposed considering the effective lateral confinement pressures provided by the stirrups and monosymmetric cross-shaped steel. The proposed equations were compared with those in three extant codes and found to exhibit improved accuracy and consistency.
\end{abstract}

\section{Introduction}

Steel-reinforced concrete (SRC) systems have received considerable research attention because of their superior structural behaviour. In an SRC structure, the steel profile is embedded into concrete. The concrete prevents local buckling of the steel profile and makes it resistant to fire damage and chemical corrosion, while the steel profile confines the concrete. These qualities provide SRC structures with high strength, toughness, and ductility [1-3]. Therefore, SRC structures are extensively used in various applications.

Typically, SRC columns have symmetrical steel sections (e.g., H- or cross-shaped). However, with rapid economic advances and increasingly stringent architectural requirements, unsymmetrical steel sections are becoming more common in engineered structures as designers seek to satisfy uneven forced states or other architectural limitations [4]. Common architectural design principles include flush faces of beams and columns in which the axes of the beam and column do not coincide [5]. Figure 1 shows three types of flush-face SRC beam-column joints: corner, border, and interior. Additionally, L-shaped, T-shaped, and monosymmetric cross-shaped steel may be applied to an SRC column to connect it with the steel profile inside an SRC beam and achieve a flush face [6].

Several researchers have investigated the structural performance of SRC columns with symmetrical steel profiles under various loading conditions, including axial compression $[7,8]$, eccentric compression $[9,10]$, and seismic loading $[11,12]$. However, relatively few test data have been made available to date regarding the structural performance of SRC columns with unsymmetrical steel profiles. Roik and Bergmann [13] designed a method for computing the eccentric bearing capacity of SRC columns with unsymmetrical cross sections and verified the viability of the method via testing. Chen et al. [5] investigated the cyclic behaviour of SRC members with T-shaped steel and found that the cross section shape had a considerable impact on the cyclic behaviour and failure modes of the members. Zeng et al. [6] conducted a study on the seismic performance of SRC columns with T-shaped and L-shaped steel. The results showed that the hysteresis loops were asymmetrical. Nishimura et al. [14] investigated the flexural behaviour of SRC columns with $\mathrm{T}$-shaped steel via experiments. The results indicated that the 


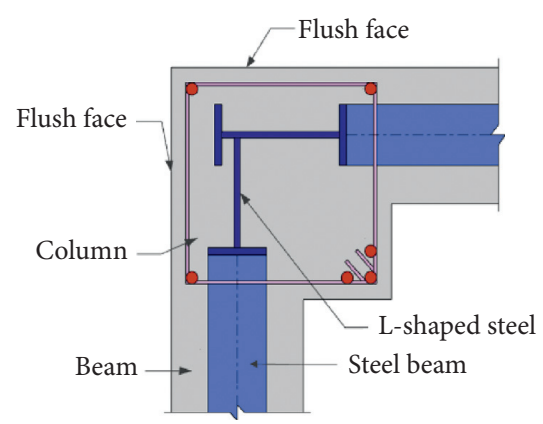

(a)

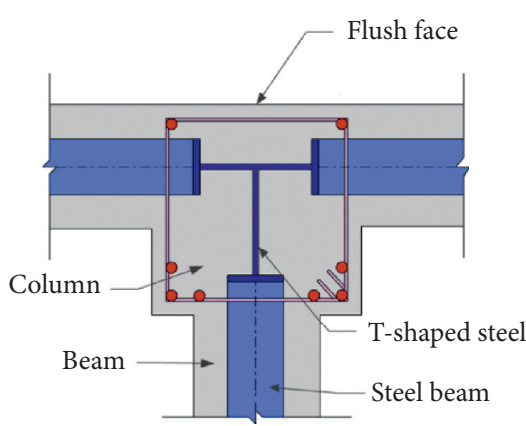

(b)

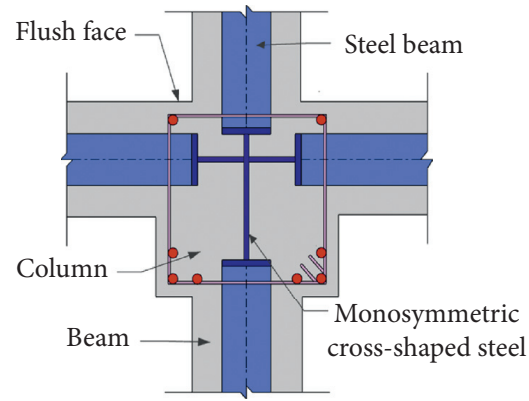

(c)

FIgURE 1: Three types of beam-column joints: (a) corner, (b) border, and (c) interior.

ultimate flexural strengths in the positive and negative loading directions were dependent on the amount of steel and reinforcing bars placed on the flexural tension side. In summary, unsymmetrical steel has been found to significantly affect the structural behaviour of SRC columns, which implies that the existing knowledge regarding SRC columns with symmetrical steel profiles cannot be used to directly analyse SRC columns with unsymmetrical steel profiles. In addition, existing studies have primarily focused on the cyclic performance of SRC columns with T- or L-shaped steel sections; few have considered the static behaviour of SRC columns with unsymmetrical steel sections, particularly monosymmetric cross-shaped steel sections.

In an SRC column, the stirrups and steel profile can improve the strength and deformability of the inner concrete. Researchers have explored the concrete constraint effect of stirrups [15-18]. The lateral restraining of concrete by crossshaped steel has been extensively researched by Chen and $\mathrm{Wu}$ [19], Chen and Lin [20], Yang et al. [21], and Zhao et al. [22]. However, the existing analysis model of confined concrete was established in accordance with symmetric cross-shaped steel and may not be suitable for monosymmetric cross-shaped steel. Therefore, the confinement stress provided by monosymmetric cross-shaped steel acting on concrete merits further research. This study accordingly focused on the behaviour of concrete confined by such a steel profile. In this study, nine specimens-eight steel-reinforced concrete columns with monosymmetric cross-shaped steel (SRCC-MCSs) and one steel-reinforced concrete column with cross-shaped steel (SRCC-CS)-were subjected to pure compression. The key parameters investigated in this study were the cross-shaped steel eccentricity ratio, concrete strength, steel ratio, and stirrup spacing. These parameters were evaluated in terms of their effects on the failure mode, load-strain curves, and loaddisplacement curves. Two methods were then established to compute the axial capacities of SRCC-MCSs, and their performance was verified through comparison with three methods based on ACI 318-14 [23], EN 1994-1-1 [24], and JGJ 138-2016 [25], as well as with the experimental results.

\section{Experimental Procedure}

2.1. Specimens. A total of nine stub column test specimens-eight SRCC-MCSs and one SRCC-CS-were subjected to axial compression. Owing to the load limits of the experimental equipment, each stub column had a cross section of $450 \mathrm{~mm} \times 300 \mathrm{~mm}$ and a height of $900 \mathrm{~mm}$ (Figure 2) to ensure that the specimens would fail in axial compression [26]. The steel profile was welded using grade Q235 steel plate, and the thicknesses of the web and flange of all specimens are as listed in Table 1. Fourteen grade HRB400 bars with a $16 \mathrm{~mm}$ diameter were used as longitudinal reinforcement. Stirrups and cross ties consisting of grade HRB335 bars with a $12 \mathrm{~mm}$ diameter were placed in the cross section as well. The concrete cover thicknesses of the reinforcement and the steel profile were $20 \mathrm{~mm}$ and $60 \mathrm{~mm}$, respectively, as shown in Figure 2(a).

The key parameters investigated were the cross-shaped steel eccentricity ratio $e_{\mathrm{a}} / h(0,0.1$, and 0.2$)$, cubic compression strength of the concrete $f_{\mathrm{cu}}(\mathrm{C} 30, \mathrm{C} 40$, and C50), steel profile ratio $\rho_{\mathrm{a}}(5.70 \%, 6.89 \%$, and $7.56 \%)$, and stirrup spacing $s(100 \mathrm{~mm}, 150 \mathrm{~mm}$, and $200 \mathrm{~mm})$. Herein, the cross-shaped steel eccentricity $\left(e_{\mathrm{a}}\right)$ is defined as the distance from the axis $\left(O_{\mathrm{a}}\right)$ of the eccentric $\mathrm{H}$-shaped steel to the centreline $(O)$ of the cross section of the SRCC-MCS, as shown in Figure 2(a). The cross-shaped steel eccentricity ratio is then defined as the cross-shaped steel eccentricity $\left(e_{\mathrm{a}}\right)$ over the column section height $(h)$ in the direction of $\mathrm{H}$-shaped steel eccentricity. Technical specification JGJ 3-2010 restricts the eccentricity between the centrelines of the beam and column to less than $1 / 4$ of the width of the column section in the beam eccentric direction [27]. Therefore, cross-shaped steel eccentricity ratios $\left(e_{\mathrm{a}} / h\right)$ of 0.1 and 0.2 were employed in this study. The steel profile ratio of the specimen is defined as $A_{a} / A$, in which $A_{a}$ is the crosssectional area of the steel profile and $A$ is the total area of the specimen section. The steel profile ratios $\left(\rho_{\mathrm{a}}\right)$ employed in this study ranged from $5.70 \%$ to $7.56 \%$, satisfying the limits $4 \%<\rho_{\mathrm{s}}<15 \%$ as per JGJ 138-2016 [25]. The maximum stirrup spacing $(s)$ was $200 \mathrm{~mm}$, which ensured that no stirrups were spaced at more than 15 times the longitudinal bar diameter [25]. Table 1 shows the detailed parameters of the specimens, in which the specimen nomenclature is defined as follows with specimen E0-C40-T8/ 10 -S150 as an example: E0 denotes the cross-shaped steel eccentricity, C40 denotes the concrete strength grade, T8/10 denotes the thicknesses of the web/flange, and S150 denotes the stirrup spacing. 


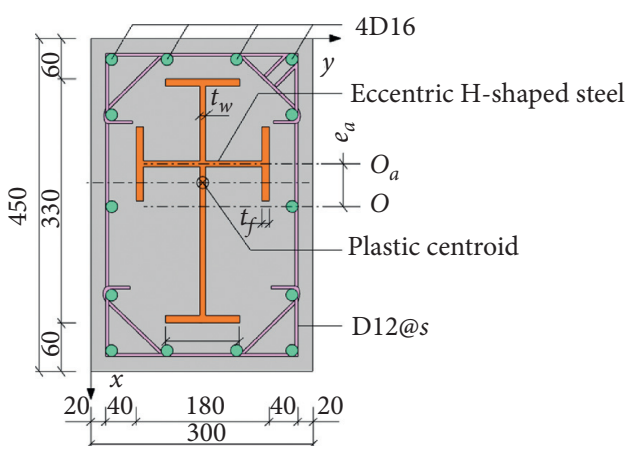

(a)

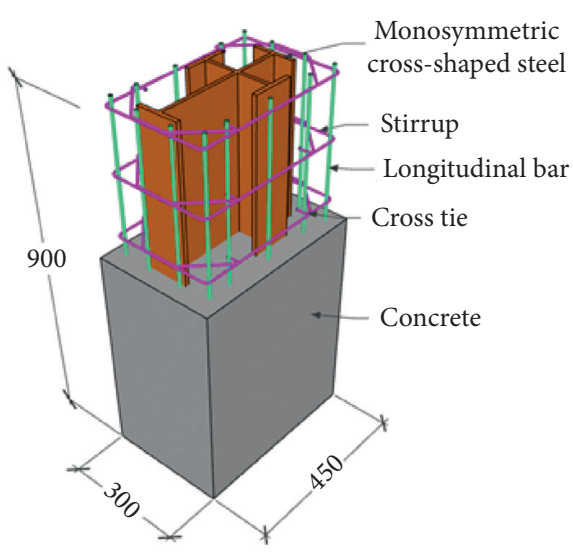

(b)

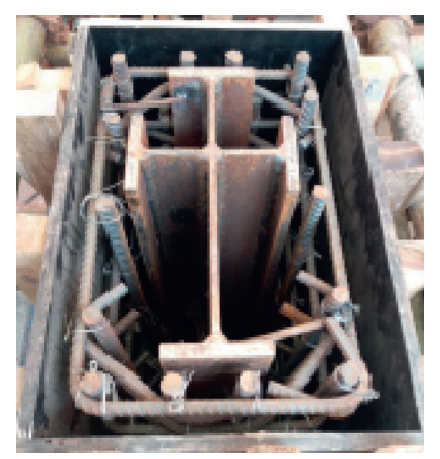

(c)

FIGURE 2: Schematic diagram of specimens: (a) cross section, (b) schematic view, and (c) photograph.

TABLE 1: Test specimens.

\begin{tabular}{|c|c|c|c|c|c|c|c|c|c|c|}
\hline Specimen & $b \times h(\mathrm{~mm})$ & $H(\mathrm{~mm})$ & $f_{\mathrm{cu}}(\mathrm{MPa})$ & $s(\mathrm{~mm})$ & $t_{\mathrm{w}}(\mathrm{mm})$ & $t_{\mathrm{f}}(\mathrm{mm})$ & $e_{\mathrm{a}}(\mathrm{mm})$ & $e_{\mathrm{a}} / h$ & $\rho_{\mathrm{a}}(\%)$ & $\rho_{\mathrm{v}}(\%)$ \\
\hline E0-C40-T8/10-S150 & $300 \times 450$ & 900 & 44.8 & 150 & 8 & 10 & 0 & 0 & 5.70 & 1.30 \\
\hline E50-C40-T8/10-S150 & $300 \times 450$ & 900 & 44.8 & 150 & 8 & 10 & 50 & 0.1 & 5.70 & 1.30 \\
\hline E100-C40-T8/10-S150 & $300 \times 450$ & 900 & 44.8 & 150 & 8 & 10 & 100 & 0.2 & 5.70 & 1.30 \\
\hline E50-C30-T8/10-S150 & $300 \times 450$ & 900 & 35.8 & 150 & 8 & 10 & 50 & 0.1 & 5.70 & 1.30 \\
\hline E50-C50-T8/10-S150 & $300 \times 450$ & 900 & 51.5 & 150 & 8 & 10 & 50 & 0.2 & 5.70 & 1.30 \\
\hline E50-C40-T8/14-S150 & $300 \times 450$ & 900 & 44.8 & 150 & 8 & 14 & 50 & 0.2 & 6.89 & 1.30 \\
\hline E50-C40-T10/14-S150 & $300 \times 450$ & 900 & 44.8 & 150 & 10 & 14 & 50 & 0.2 & 7.56 & 1.30 \\
\hline E50-C40-T8/10-S100 & $300 \times 450$ & 900 & 44.8 & 100 & 8 & 10 & 50 & 0.2 & 5.70 & 1.96 \\
\hline E50-C40-T8/10-S200 & $300 \times 450$ & 900 & 44.8 & 200 & 8 & 10 & 50 & 0.2 & 5.70 & 0.98 \\
\hline
\end{tabular}

Note. $b$ and $h$ are the width and height of the cross section, $H$ is the column height, $t_{\mathrm{w}}$ is the thickness of the web, $t_{\mathrm{f}}$ is the thickness of the flange, and $\rho_{\mathrm{v}}$ is the volume-stirrup ratio.

For the SRCC-MCS, the centreline $(O)$ of the cross section is not identical to the plastic centroidal axis $\left(O_{\mathrm{p}}\right)$, as shown in Figure 2(a). To ensure that the SRCC-MCS specimens would be subjected to pure compression, the "plastic centroid" was determined to apply the axial load [13], as shown in Figure 2(a). The coordinate of the "plastic centroid" can be calculated as follows:

$$
\left\{\begin{array}{l}
x_{p c}=\frac{x_{c} A_{c} f_{c o}+x_{r} A_{r} f_{y r}+x_{a} A_{a} f_{y a}}{A_{c} f_{c o}+A_{r} f_{y r}+A_{a} f_{y a}} \\
y_{p c}=\frac{y_{c} A_{c} f_{c o}+y_{r} A_{r} f_{y r}+y_{a} A_{a} f_{y a}}{A_{c} f_{c o}+A_{r} f_{y r}+A_{a} f_{y a}},
\end{array}\right.
$$

where $A_{\mathrm{c}}$ and $A_{\mathrm{r}}$ are the cross-sectional areas of the concrete and longitudinal bars, respectively; $x_{\mathfrak{c}}, x_{\mathrm{r}}$, and $x_{\mathrm{a}}$ are the distances to the respective centres of gravity from the $x$-axis; $y_{c}, y_{\mathrm{r}}$, and $y_{\mathrm{a}}$ are the distances to the respective centres of gravity from the $y$-axis; $f_{\text {co }}$ is the cylinder compressive strength of the concrete $\left(f_{\mathrm{co}}=0.8 f_{\mathrm{cu}}\right)$ [26]; and $f_{\mathrm{yr}}$ and $f_{\mathrm{ya}}$ are the yield strengths of the longitudinal bar and steel profile, respectively.

2.2. Material Properties. Standard concrete cubes $(150 \mathrm{~mm} \times 150 \mathrm{~mm} \times 150 \mathrm{~mm})$ were tested based on Chinese Standard GB/T 50081-2010 [28], and the average cubic compressive strengths are summarised in Table 1. Coupons were cut from steel plates with different thicknesses and from reinforcement bars with different diameters to measure the mechanical properties of the steel based on Chinese Standard GB/T 228.1-2010 [29], and the results are listed in Table 2.

2.3. Test Setup and Instrumentation. The experimental equipment employed in this study was a $30,000 \mathrm{kN}$ pressure testing machine (Figure 3(a)). The actuator end was connected to the loading plate with a spherical hinge to allow the loading plate to be rotated. An axial compressive load was applied to the "plastic centroid" of the specimen cross section to ensure that the specimen would be under pure compression (Figure 2(a)) [13, 30]. Before the test, two endcapping devices were mounted on both ends of each specimen to prevent local damage to the end zones (Figure 3(b)). During the loading process, the specimens were subjected to an axial load that was statically increased at a rate of $0.3 \mathrm{~mm} / \mathrm{min}$ [21]. The test was terminated once the load dropped to $60 \%$ of the peak load.

The vertical shortening of the specimens was measured using two linear variable displacement transducers (LVDTs) located at each end of each column (Figure 3(b)). The development of the strains in the longitudinal bars, stirrups, steel profile, and concrete of each specimen was measured 
TABLE 2: Material properties.

\begin{tabular}{lcccccc}
\hline Reinforcement & Thickness/diameter $(\mathrm{mm})$ & Steel grade & $f_{\mathrm{y}}(\mathrm{MPa})$ & $f_{\mathrm{u}}(\mathrm{MPa})$ & $E_{\mathrm{s}}\left(\times 10^{5} \mathrm{MPa}\right)$ & $\varepsilon_{\mathrm{y}}\left(\times 10^{-6}\right)$ \\
\hline & 8 & Q235 & 384.3 & 455.9 & 2.08 & 1847 \\
Steel plate & 10 & & 371.2 & 442.8 & 2.03 & 1829 \\
& 14 & & 310.4 & 420.1 & 2.07 & 1469 \\
Stirrup & 12 & HRB335 & 433.6 & 561.2 & 2.10 & 2067 \\
Longitudinal bar & 16 & HRB400 & 518.0 & 633.9 & 2.06 & 2527 \\
\hline
\end{tabular}

Note. $f_{\mathrm{y}}$ is the yield strength, $f_{\mathrm{u}}$ is the ultimate strength, $E_{\mathrm{s}}$ is the elastic modulus, and $\varepsilon_{\mathrm{y}}$ is the yield strain.

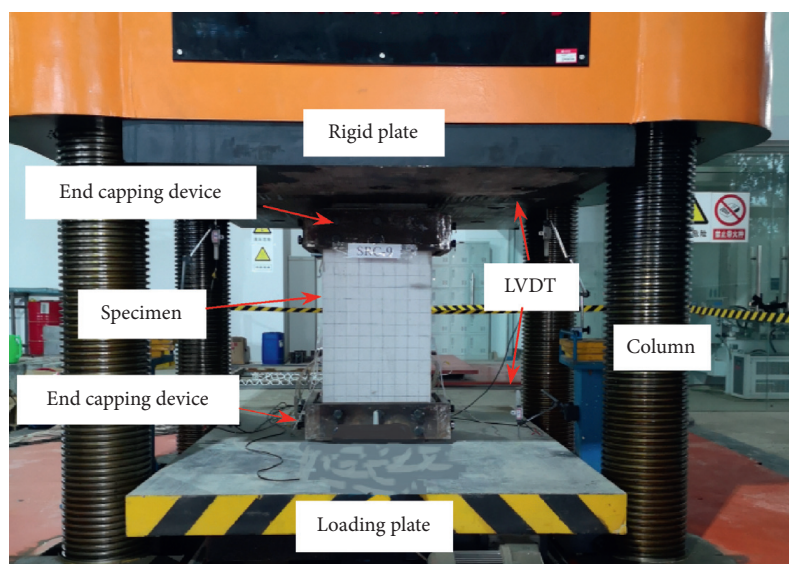

(a)

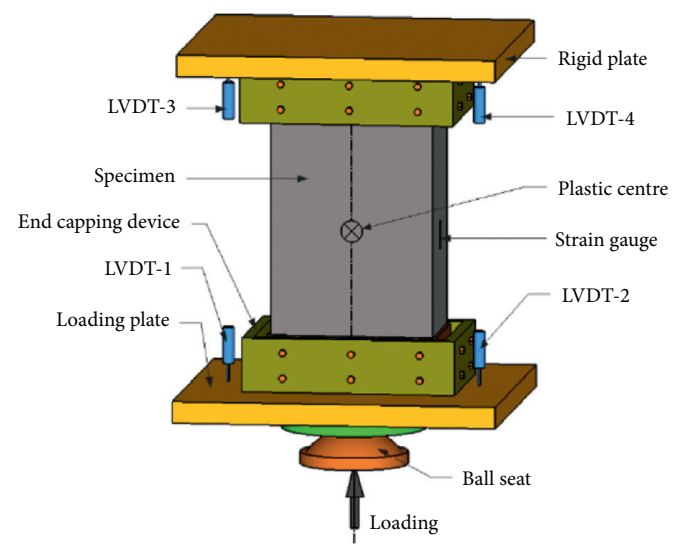

(b)

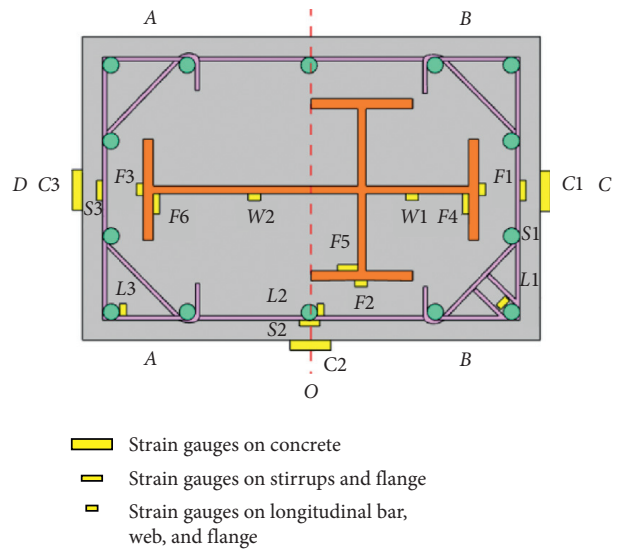

(c)

Figure 3: Test setup and instrumentation: (a) photograph of test setup, (b) test setup and layout of LVDTs, and (c) layout of the strain gauges.

using strain gauges attached at the specimen midheight, as illustrated in Figure 3(c). Three strain gauges were bonded to the longitudinal bars at the midside and corners to monitor the vertical deformation. Three strain gauges were bonded to the stirrups at the midsection. Strain gauges were also attached to the flange and web to record their axial and transverse deformation. Three strain gauges were pasted on each specimen to monitor the longitudinal deformation of the concrete.

\section{Test Results and Discussion}

3.1. Failure Mode and Test Observations. For convenience, the sides of the specimens were labelled A, B, C, and D, as shown in Figure 3(c). All SRCC-MCS specimens failed in a relatively similar manner; hence, the failure of E100-C40T8/10-S150 is discussed here as an example. The failure process could be divided into four stages:

(1) In the elastic working stage, the specimen exhibited a linear behaviour with no evident cracking on its surface.

(2) Once the load reached approximately $80 \%$ of the peak load, the steel profile and longitudinal bars began to yield, indicating that the specimen had begun to enter the elastic-plastic stage. Several minute cracks appeared on the tops of the specimens, most of which were centred on surfaces A and D. As the loading progressed, the cracks on surfaces A and $\mathrm{D}$ widened and rapidly propagated to the bottom of 
the specimen, while the cracks on surfaces B and C developed slowly.

(3) As the loading displacement increased, one main crack developed on surface A as the peak load was reached. The concrete cover of surface $\mathrm{D}$ began to spall, and the axial load dropped suddenly, indicating that the specimen had entered the descending stage.

(4) Once the load dropped to approximately $70 \%$ of the peak load, the specimen entered the softening stage. The axial load decreased gradually and steadily as the loading displacement increased, and the longitudinal bars near surface $\mathrm{D}$ began to buckle because of the spalling of the concrete cover. Moreover, local buckling of the longitudinal bars led to further cover spalling as well as outward bending of the stirrups. At this stage, most of the axial loading was borne by the steel profile.

Figure 4(a) shows the typical failure modes of the specimens. After the concrete of the specimens was removed, the steel flanges presented slight outward bulges where the concrete had collapsed, as depicted in Figure 4(b). Generally, most of the damage to the specimens was concentrated on surfaces A and D.

The typical failure processes of SRCC-CS (E0-C40-T8/ 10 -S150) constituted yielding of the steel profile and longitudinal bars, followed by crushing of the concrete at the midheight of the specimen, and then buckling of the longitudinal bars, fracturing of the stirrups, and slight outward bulging of the opposite steel flanges. In summary, the damage to the specimen was relatively uniform, as shown in Figure 4. Upon comparing the failure modes of the SRCCMCSs and SRCC-CS, it was observed that the monosymmetric cross-shaped steel determined the failure location of SRCC-MCS specimens.

3.2. Strain Development. Figure 5 describes the strain distribution in the steel profile, concrete, and stirrups at the midheight cross section of typical specimens E0-C40-T8/10S150 and E100-C40-T8/10-S150. The law of strain development in the specimens can be described as follows:

(1) Figure 5(a) illustrates the strains in the concrete and steel profile along the axis of symmetry for the steel profile. For E100-C40-T8/10-S150, the strains in the concrete and steel profile increased at the same rate in the early loading stages, which indicates that the concrete had bonded well with the steel profile. After the load reached $80 \%$ of the peak load, the strain growth was accelerated, and the strain developed nonuniformly. The strain at gauge F-3 developed faster than the strains at gauges $\mathrm{W}-2, \mathrm{~W}-1$, and $\mathrm{F}-1$. These phenomena confirm the observation of more extensive longitudinal cracks on surfaces $\mathrm{A}$ and D. These phenomena can likely be attributed to the fact that the restraint effect of the monosymmetric cross-shaped steel is not uniform and concentrates the damage in the specimen away from the eccentric $\mathrm{H}$-shaped steel. However, the steel web and flange still reached their yield strengths prior to the peak load. For E0-C40-T8/10-S150, the strain of the steel profile and concrete increased in a uniform manner in different locations and reached its yield strength before the load reached the peak load. At the peak load, the concrete reached its ultimate compression strain of $3300 \mu \varepsilon$.

(2) Figure 5(b) shows the development of the strain in the stirrups. For E100-C40-T8/10-S150, the strain increased slowly in the early loading stages, indicating that the stirrups provided negligible lateral confinement. After the load reached $80 \%$ of the peak load, the lateral strain increased rapidly, and the strain at gauge S-2 developed faster than the strains at gauges S-3 and S-1. This is likely because the transverse expansion of the concrete resulted in bending deformation of the stirrups and because the bending rigidity of the stirrups was smaller along the length of the specimen than along the width. Furthermore, the cross ties may bear part of the lateral load along the width. In addition, the strain at gauge S-3 developed faster than that at gauge S-1. Because the lateral confinement stress provided by the monosymmetric cross-shaped steel was concentrated on the eccentric H-shaped steel section (Figure 2(a)), the expansive deformation of the concrete near the $\mathrm{H}$-shaped steel was relatively small [22]. For E0-C40-T8/10-S150, the strain monitored by $\mathrm{S}-1$ and $\mathrm{S}-3$ increased at the same rate after load reached approximately $80 \%$ of the peak load. The stirrup yielded before the peak load, which agrees with the observation of Yang et al. [21]. This indicates that the hoops enhanced the confinement of the inner concrete at the ultimate stage as it deformed through expansion.

\subsection{Load-Displacement Relationship for Specimens.} Figure 6 describes the effects of the evaluated parameters on the axial load-displacement curves of the specimens. Table 3 lists the yield, peak, and ultimate loads as well as the corresponding axial displacements and ductility indexes of the specimens. The universal yielding-bending moment method was used to obtain the yield point [31]. The definition of ductility index given by Liu et al. [32] was utilised:

$$
\mu=\frac{\Delta_{u}}{\Delta_{y}},
$$

where $\Delta_{\mathrm{u}}$ is the displacement corresponding to $85 \%$ of the peak load in the descending branch and $\Delta_{\mathrm{y}}$ is the displacement corresponding to the yield load.

The following findings were obtained according to the results in Table 3 and Figure 6:

(1) Figure 6(a) and Table 3 show that the axial capacity and ductility of the specimens decreased with increasing cross-shaped steel eccentricity ratio. The axial capacity and ductility index of E100-C40-T8/ $10-\mathrm{S} 150$ were $5.19 \%$ and $27.16 \%$ lower than those of 


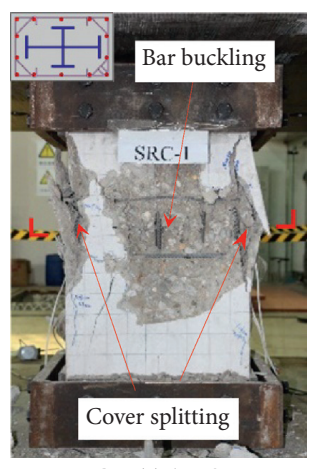

E0-C40-T8/10-S150

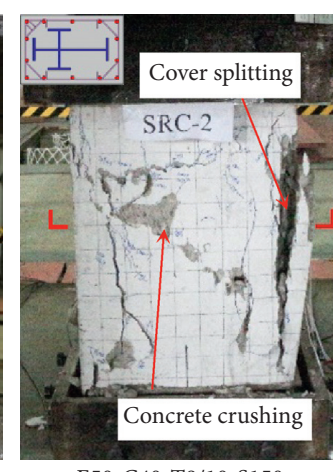

E50-C40-T8/10-S150

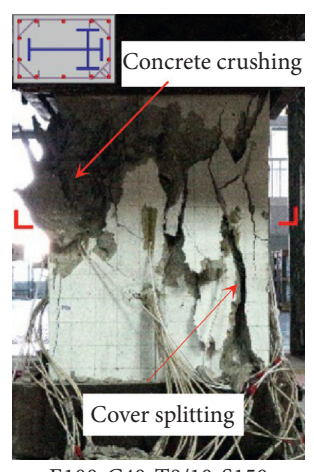

E100-C40-T8/10-S150

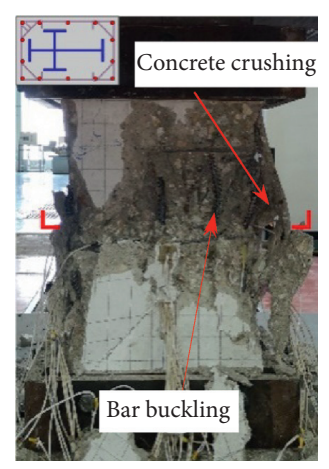

E50-C30-T8/10-S150

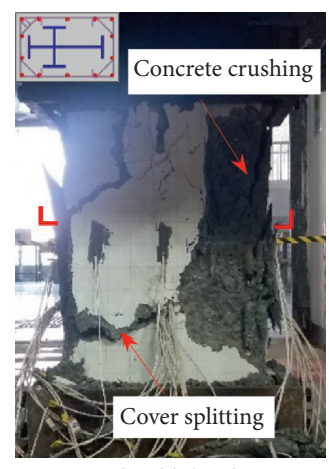

E50-C50-T8/10-S150

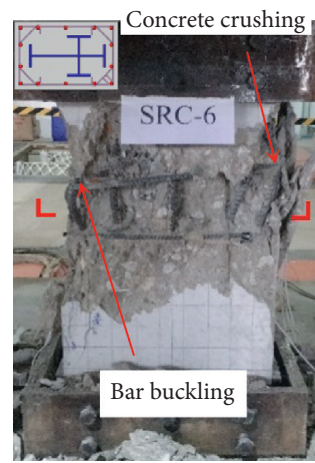

E50-C40-T8/14-S150

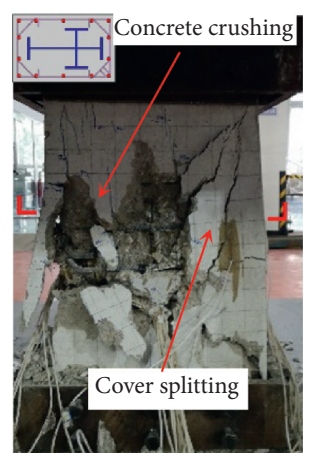

E50-C40-T10/14-S150

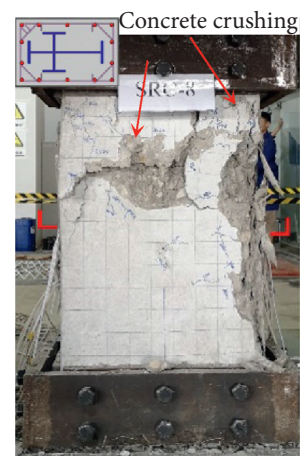

E50-C40-T8/10-S100

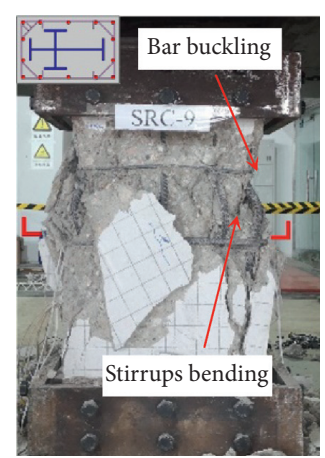

E50-C40-T8/10-S200

(a)
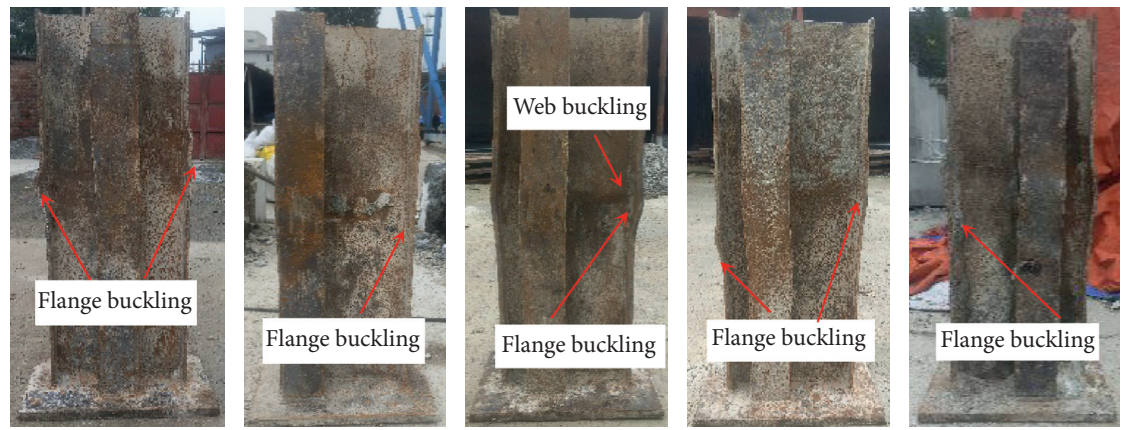

E0-C40-T8/10-S150 E100-C40-T8/10-S150 E50-C40-T

(b)

FIGURE 4: (a) Failure modes of specimens and (b) local buckling of the steel profile.

E0-C40-T8/10-S150, respectively. This is probably because the steel profile enhanced the strength and deformability of the concrete [19-22]. In the SRCCMCS specimens, the lateral confining action of the steel profile was unsymmetrical. However, the confinement efficiency was related to the uniformity of the confinement [33]. As a result, the confining stress of the steel profile on the concrete became less significant as the cross-shaped steel eccentricity ratio increased. After the peak load, the inner concrete away from the eccentric $\mathrm{H}$-shaped steel began to be crushed, which led to nonuniform stress distribution along the cross section of the SRCC-MCS. The specimen then suffered a sudden loss of axial capacity. Therefore, the cross-shaped steel eccentricity ratio negatively affected the axial compression behaviour of the SRCC-MCS specimens. The crossshaped steel eccentricity ratio must therefore be strictly controlled during practical engineering design.

(2) Figure 6(b) and Table 3 show that the increase in concrete strength enhanced the axial capacity and initial stiffness of the specimens. As the concrete strength increased from $35.8 \mathrm{MPa}$ to $51.5 \mathrm{MPa}$, the axial capacity increased from $9046 \mathrm{kN}$ to $11293 \mathrm{kN}$. This is equivalent to a strength increase of $24.84 \%$; however, it was accompanied by a $38.54 \%$ decrease in the ductility index. The reason for this observation is that confinement efficiency decreases as concrete strength increases [33]. Subsequently, the load on E50-C50-T8/10-S150 dropped suddenly after the peak load was reached because the cover had spalled. 

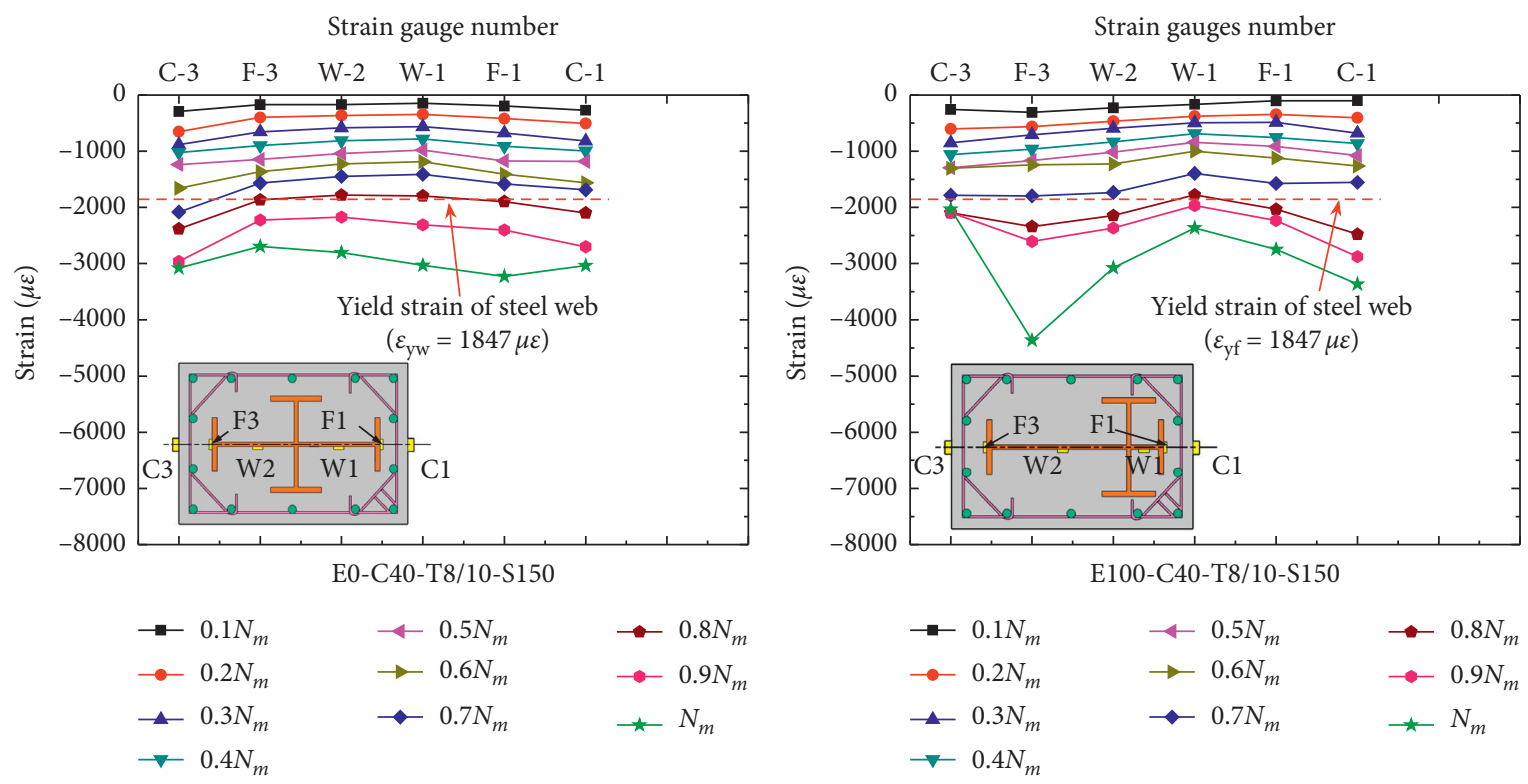

(a)
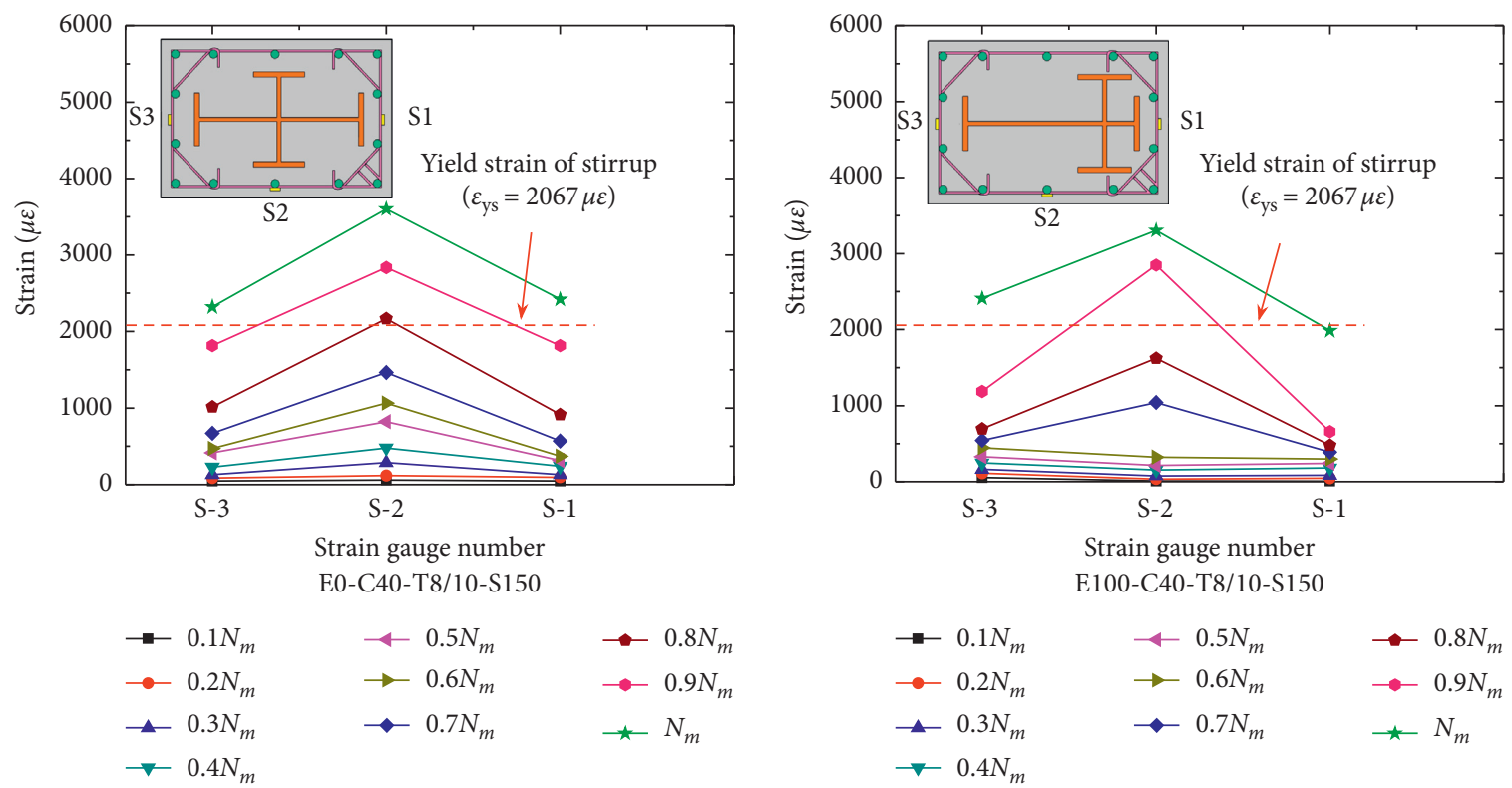

(b)

FIGURE 5: Strain analysis: (a) strain in the concrete and steel profile and (b) strain in the stirrups.

These observations indicate that concrete grades from C30 to C60 and steel profile grades from Q235 to Q420 should be adopted for SRCC-MCS construction [25]. Moreover, the ratio of the standard yield strength of the steel profile to the standard axial compressive strength of the concrete should be about $10: 1$ based on common applications in practical engineering design [34].

(3) Figure 6(c) and Table 3 show that the axial capacity and ductility of the specimens gradually increased with increasing steel ratio. The axial capacity and ductility indices of E50-C40-T10/14-S150 were $6.04 \%$ and $7.83 \%$ higher than those of E50-C40-T8/ 10-S150, respectively. Thus, a higher steel ratio improved the axial behaviour of the specimens. The high strength and plastic deformability of the steel allowed the steel profile to resist a greater load at higher steel ratios. This observation can also be attributed to the lateral confinement provided by the steel profile, which enhanced the strength and deformability of the inner concrete [19-22]. A thicker steel flange may provide more confinement and enhance the axial compressive strength of SRCC-MCS to a certain extent. Therefore, the axial compression behaviour of SRCC-MCSs can be improved by increasing the steel ratio.

(4) Figure 6(d) and Table 3 show that the axial capacity and ductility of the SRCC-MCSs decreased with 


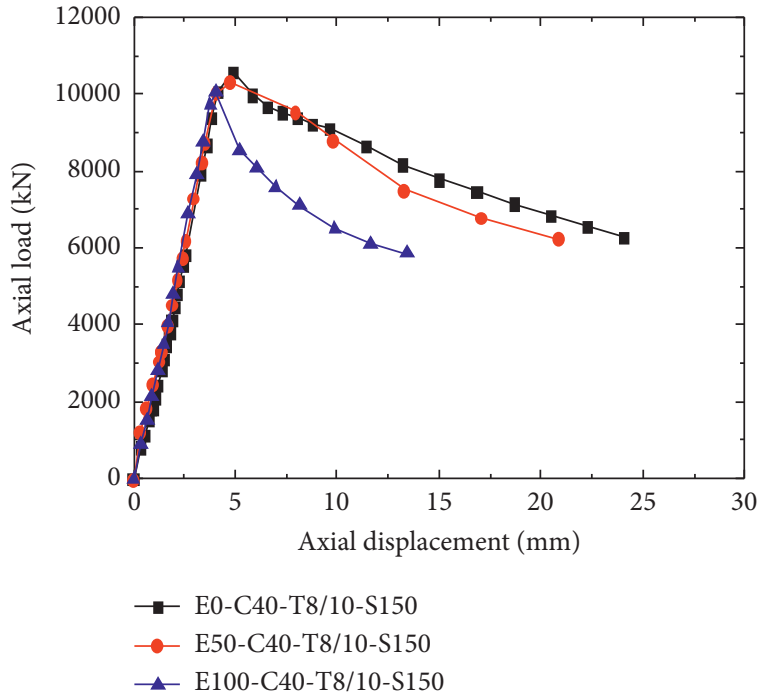

(a)

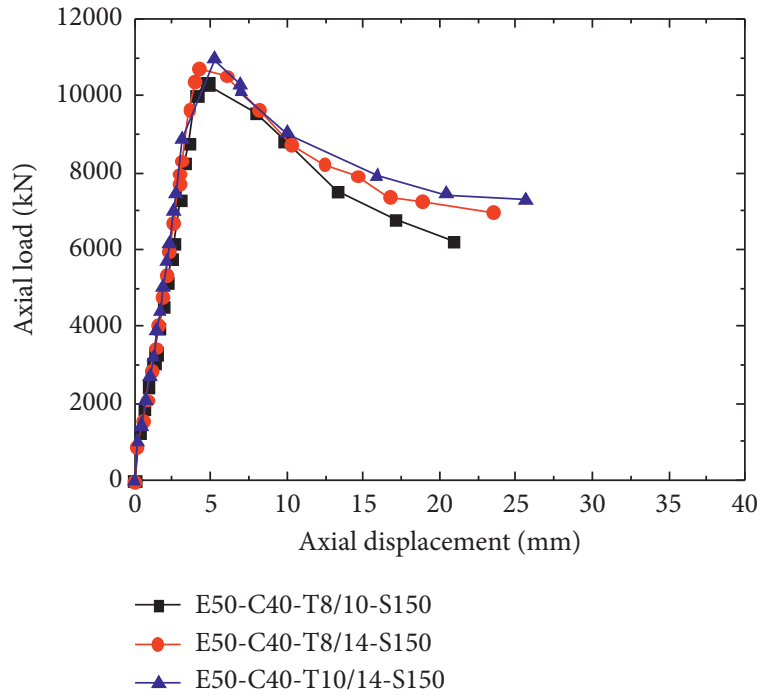

(c)

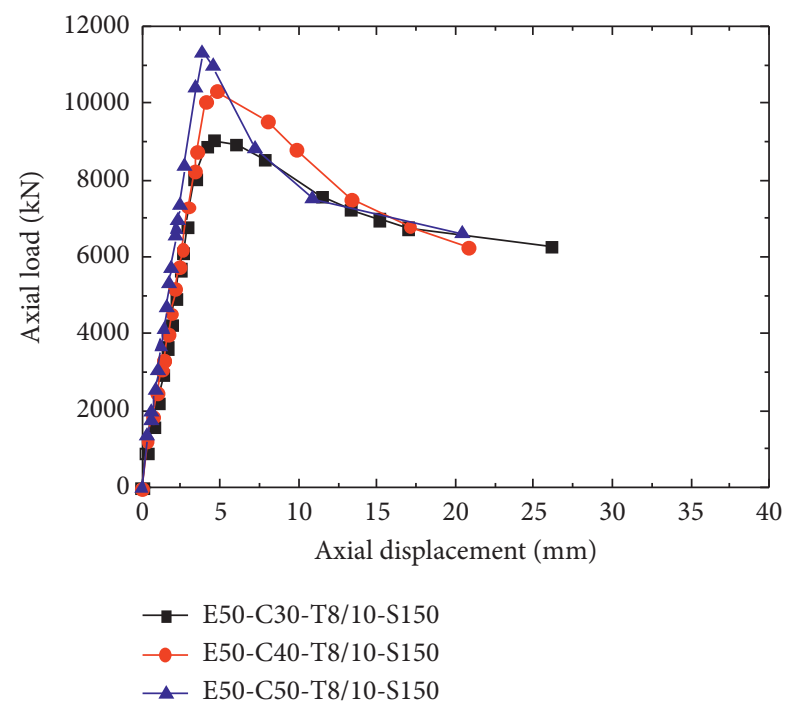

(b)

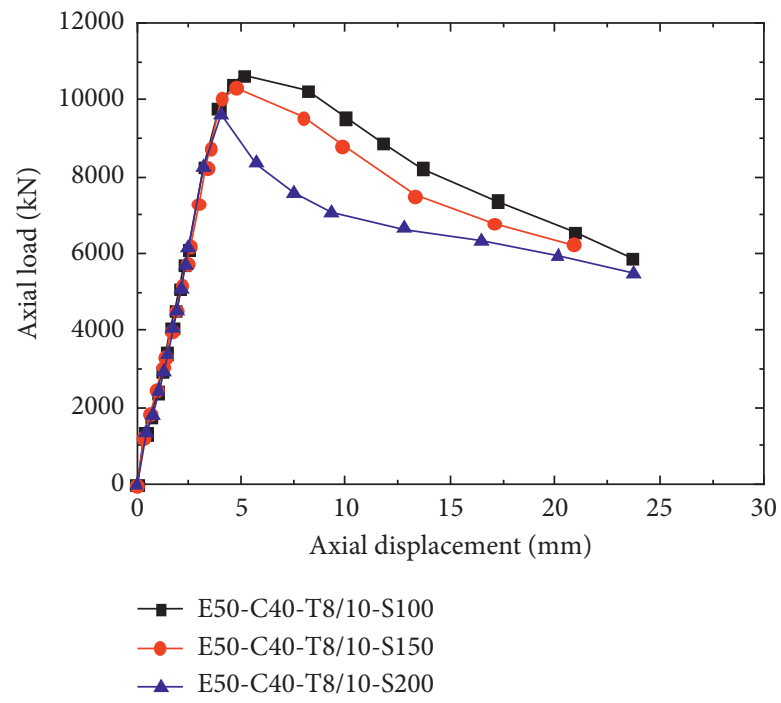

(d)

Figure 6: Axial load-displacement curves according to (a) cross-shaped steel eccentricity ratio, (b) concrete strength, (c) steel profile ratio, and (d) stirrup spacing.

TABLE 3: Test results.

\begin{tabular}{|c|c|c|c|c|c|c|}
\hline Specimen & $N_{\mathrm{y}}(\mathrm{kN})$ & $\Delta_{\mathrm{y}}(\mathrm{mm})$ & $N_{\mathrm{m}}(\mathrm{kN})$ & $\Delta_{\mathrm{m}}(\mathrm{mm})$ & $\Delta_{\mathrm{u}}(\mathrm{mm})$ & $\mu$ \\
\hline E0-C40-T8/10-S150 & 10208 & 4.61 & 10579 & 5.26 & 11.2 & 2.43 \\
\hline E50-C40-T8/10-S150 & 10097 & 4.08 & 10321 & 4.77 & 9.40 & 2.30 \\
\hline E100-C40-T8/10-S150 & 9629 & 4.24 & 10030 & 4.45 & 7.50 & 1.77 \\
\hline E50-C30-T8/10-S150 & 8606 & 3.84 & 9046 & 4.46 & 11.04 & 2.88 \\
\hline E50-C50-T8/10-S150 & 10984 & 3.72 & 11293 & 4.55 & 6.57 & 1.77 \\
\hline E50-C40-T8/14-S150 & 10336 & 3.95 & 10711 & 4.24 & 9.60 & 2.43 \\
\hline E50-C40-T10/14-S150 & 10349 & 3.72 & 10944 & 5.23 & 9.21 & 2.48 \\
\hline E50-C40-T8/10-S100 & 9976 & 4.11 & 10640 & 5.15 & 11.33 & 2.76 \\
\hline $\mathrm{E} 50-\mathrm{C} 40-\mathrm{T} 8 / 10-\mathrm{S} 200$ & 9398 & 3.91 & 9603 & 4.03 & 7.12 & 1.82 \\
\hline
\end{tabular}

Note. $N_{\mathrm{y}}$ is the yield load and $\Delta_{\mathrm{m}}$ is the displacement corresponding to the peak load.

increasing stirrup spacing. The stirrup spacings of E50-C40-T8/10-S100, E50-C40-T8/10-S150, and E50-C40-T8/10-S200 were 100,150 , and $200 \mathrm{~mm}$, respectively, and their corresponding axial bearing capacities were $10,640,10,321$, and $9,603 \mathrm{kN}$, respectively; thus, the axial bearing capacities for the 
150 and $200 \mathrm{~mm}$ spacing were $3.0 \%$ and $9.75 \%$ lower than that for the $100 \mathrm{~mm}$ spacing. The ductility indices of E50-C40-T8/10-S150 and E50-C40-T8/10S200 were $16.67 \%$ and $34.06 \%$ smaller, respectively, than that of E50-C40-T8/10-S100. The axial capacity and ductility index of each specimen decreased significantly as the stirrup spacing increased. This agreed with the results obtained by Liu et al. [35]. A smaller stirrup spacing may provide a stronger confinement effect, which would increase the axial capacity and ductility. Therefore, controlling the stirrup spacing significantly influences the axial behaviour of SRCC-MCSs.

\section{Loading Capacity Prediction}

4.1. Basic Assumptions. The experimental results showed that the concrete of the specimens had bonded well with the steel profiles. The axial capacity of an SRCC-MCS can thus be calculated through a section analysis conducted by superimposing the contributions of its different constituent materials $[21,32]$. To this end, several assumptions proposed by Yang et al. [21] were utilised in this study:

(1) The axial forces on the SRCC-MCS cross section were considered uniform

(2) In the biaxial stress state, the tensile and compressive stresses in the steel profile both reached the yield strength

(3) The second-order effect was neglected

As shown in Figure 7, the cross section of an SRCC-MCS can be divided into three regions based on the different concrete constraint states: unconfined, partially confined, and highly confined [20]. The unconfined concrete lies outside a parabola with an initial tangent slope of $45^{\circ}$, the partially confined concrete is only confined by the stirrups [17], and the highly confined concrete is confined by both the steel profile and stirrups. The boundary between the highly confined and partially confined concrete also forms a parabola [19]. The axial capacity of an SRCC-MCS is thus

$$
N_{c}=A_{\mathrm{uc}} f_{\mathrm{uc}}+A_{\mathrm{pc}} f_{\mathrm{pc}}+A_{\mathrm{hc}} f_{\mathrm{hc}}+A_{\mathrm{st}} f_{\mathrm{ya}}+A_{\mathrm{sr}} f_{\mathrm{yr}},
$$

where $N_{\mathrm{c}}$ is the computed axial capacity of the column; $A_{\mathrm{uc}}$, $A_{\mathrm{pc}}, A_{\mathrm{hc}}, A_{\mathrm{st}}$, and $A_{\mathrm{sr}}$ are the cross-sectional areas of the unconfined concrete, partially confined concrete, highly confined concrete, steel profile, and longitudinal bars, respectively; and $f_{\mathrm{uc}}, f_{\mathrm{pc}}$, and $f_{\mathrm{hc}}$ are the compressive strengths of the unconfined, partially confined, and highly confined concrete, respectively.

\subsection{Strengths of Unconfined and Partially Confined Concrete.} Mander et al. [17] established a confined concrete constitutive model suitable for rectangular stirrups under pure compression. The compressive strain-stress relations in this model are

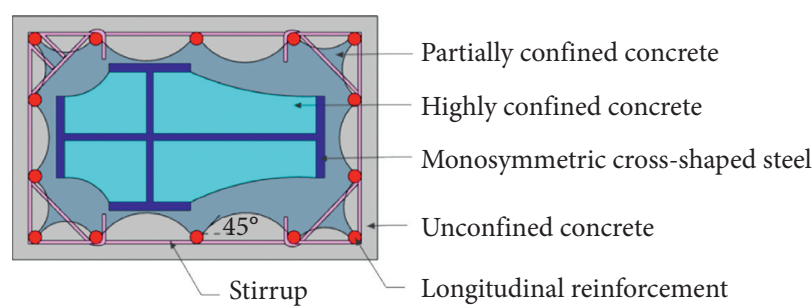

FIGURE 7: Materials in the cross section of an SRCC-MCS.

$$
\begin{aligned}
\sigma_{c} & =\frac{f_{c c} x r}{r-1+x^{r}}, \\
x & =\frac{\varepsilon_{c}}{\varepsilon_{\mathrm{cc}}} \\
r & =\frac{E_{c}}{E_{c}-E_{\mathrm{sec}}} \\
E_{c} & =5000 \sqrt{f_{c o}}, \\
E_{\mathrm{sec}} & =\frac{f_{\mathrm{cc}}}{\varepsilon_{\mathrm{cc}}}, \\
\varepsilon_{\mathrm{cc}} & =\varepsilon_{\mathrm{co}}\left[1+5\left(\frac{f_{\mathrm{cc}}}{f_{\mathrm{co}}}-1\right)\right],
\end{aligned}
$$

where $f_{\text {co }}$ and $f_{\mathrm{cc}}$ are the compressive strengths of the unconfined and confined concrete, respectively; $\varepsilon_{\mathrm{co}}$ and $\varepsilon_{\mathrm{cc}}$ are the corresponding peak strains ( $\varepsilon_{\mathrm{co}}$ is generally assumed to be 0.002$) ; E_{\mathrm{c}}$ is the tangent modulus of the concrete; and $E_{\mathrm{sec}}$ is the secant modulus of the confined concrete.

The compressive strength of the confined concrete is given by

$$
f_{\mathrm{cc}}=f_{\mathrm{co}}\left(-1.254+2.254 \sqrt{1+\frac{7.94 f_{\mathrm{le}}}{f_{\mathrm{co}}}}-2 \frac{f_{\mathrm{le}}}{f_{\mathrm{co}}}\right),
$$

where $f_{\mathrm{le}}$ is the effective lateral confining stress.

Rectangular reinforced concrete columns have different quantities of stirrups in the $x$ and $y$ directions, and the lateral confining stresses near the corners and longitudinal bars are higher than those between the corners and longitudinal bars, as depicted in Figure 8. To consider the uneven distribution of confining stress, the effective confinement coefficient $k_{\mathrm{e}}$ for stirrups is adopted. Furthermore, the effective lateral confining stresses from rectangular stirrups in the $x$ and $y$ directions can be expressed as follows [17]:

$$
\begin{gathered}
f_{\mathrm{le}, \mathrm{px}}=k_{e} \rho_{x} f_{\mathrm{yh}}, \\
f_{\mathrm{le}, \mathrm{py}}=k_{e} \rho_{y} f_{\mathrm{yh}}, \\
k_{e}=\frac{\left(1-\sum_{i=1}^{n}\left(\left(w_{i}^{\prime}\right)^{2} / 6 b_{c} d_{c}\right)\right)\left(1-\left(s^{\prime} / 2 b_{c}\right)\right)\left(1-\left(s^{\prime} / 2 d_{c}\right)\right)}{1-\rho_{c c}},
\end{gathered}
$$




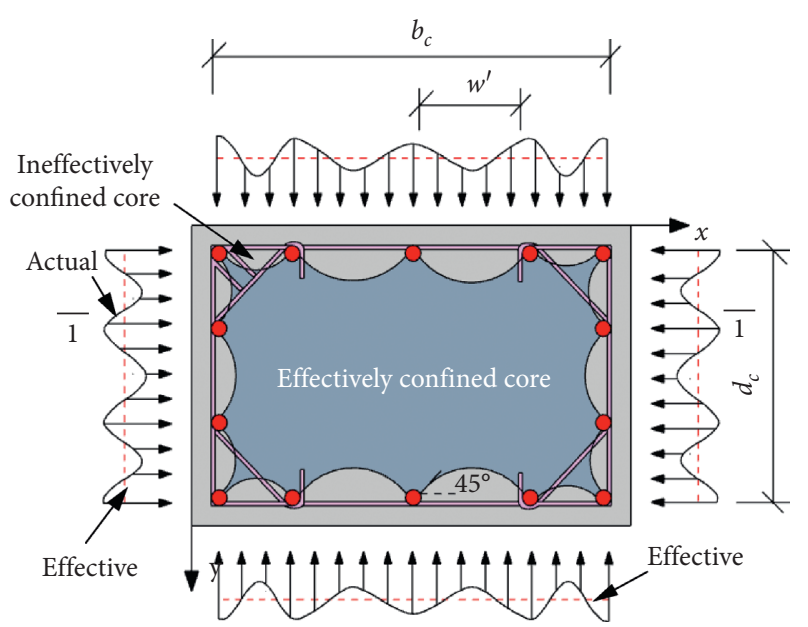

(a)

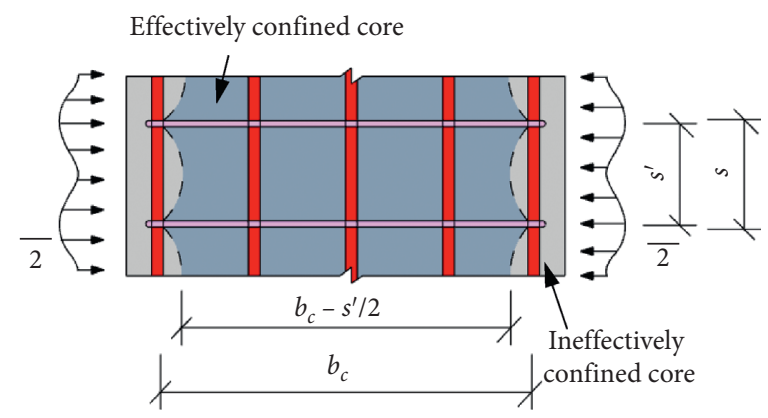

(b)

Figure 8: Effectively confined core for rectangular stirrup: (a) Section 2-2 and (b) Section 1-1.

where $f_{\mathrm{le}, \mathrm{px}}$ and $f_{\mathrm{le} \text {,py }}$ are the effective lateral confining stresses from the rectangular stirrups in the $x$ and $y$ directions, respectively; $k_{\mathrm{e}}$ is the confinement effectiveness coefficient for rectangular stirrups; $\rho_{\mathrm{x}}$ and $\rho_{\mathrm{y}}$ are the volume ratios of the transverse reinforcement in the $x$ and $y$ directions, respectively; $f_{\mathrm{yh}}$ is the yield strength of the stirrup; $b_{\mathrm{c}}$ and $d_{\mathrm{c}}$ are the core dimensions of the perimeter stirrup centrelines, where $b_{c} \geq d_{c} ; \rho_{\mathrm{cc}}$ is the ratio of the area of the longitudinal bar to that of the core section; $w_{i}^{\prime}$ is the $i$ th clear distance between adjacent longitudinal bars; and $s^{\prime}$ is the clear vertical spacing between stirrups.

The general solution for the multiaxial failure criterion in terms of the two effective lateral confining stresses is shown in Figure 9 [17]. The effective lateral confining stresses $f_{\text {le,px }}$ and $f_{\text {le,py }}$ provided by the rectangular stirrups were calculated using equations (6) and (7). The strength of the partially confined concrete $f_{\mathrm{pc}}$ was determined as illustrated in Figure 9. For the unconfined concrete, the strength was considered to be $f_{\text {co }}$ because $f_{\text {le }}=0$.

4.3. Strength of Highly Confined Concrete. In Figure 10, a quarter section of the SRCC-MCS was used to analyse the stress state of the steel profile.

Figure 11(a) shows the actual confining stress provided by the steel profile, which was mainly distributed around the intersection between adjacent webs and flanges [21, 22]. The actual confining stress provided by the steel profile can thus be simplified as shown in Figure 11(b), under the assumption that the confining stress is evenly distributed along the steel flange and web [21, 22]. The steel flange exhibited bending deformation because of expansion deformation of the core concrete. Under these conditions, the flange can be considered equivalent to a cantilever beam, as depicted in Figure 11(c).

The lateral confining stress $f_{1, \mathrm{~s}}$ can then be determined from the ultimate bending moment $M_{\mathrm{u}}$ :

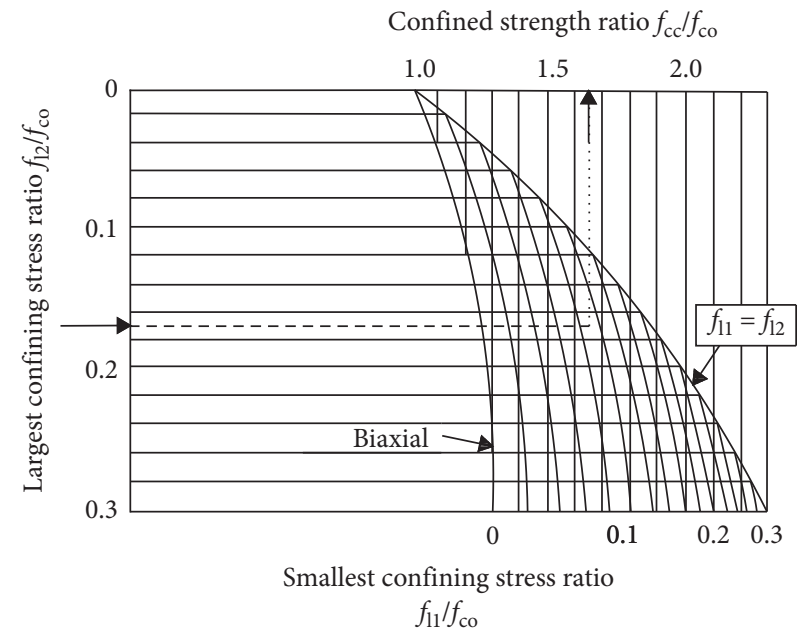

FIgURE 9: Relationship between the effective lateral confining stresses and strength of the confined concrete for rectangular sections.

$$
M_{u}=\frac{b^{2} f_{l, s}}{2} .
$$

The ultimate bending moment resistance $M_{\mathrm{p}}$ is obtained from the edge-yielding criterion of the flange [22], as shown in Figure 11(c):

$$
M_{p}=\frac{t_{f}^{2} f_{y f}}{6},
$$

where $b$ is the clear width of the flange, $t_{\mathrm{f}}$ is its thickness, and $f_{\mathrm{yf}}$ is its yield strength.

According to equations (9) and (10), the lateral confining stress $f_{1, \mathrm{~s}}$ is

$$
f_{l, s}=\frac{t_{f}^{2} f_{y f}}{3 b^{2}} .
$$




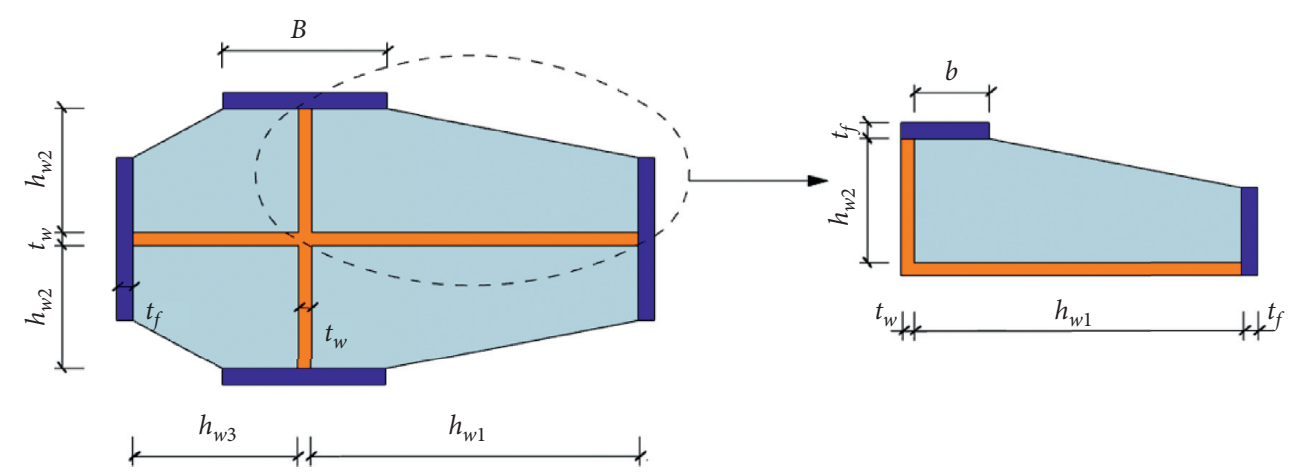

Figure 10: Cross section of the SRCC-MCS-core column.

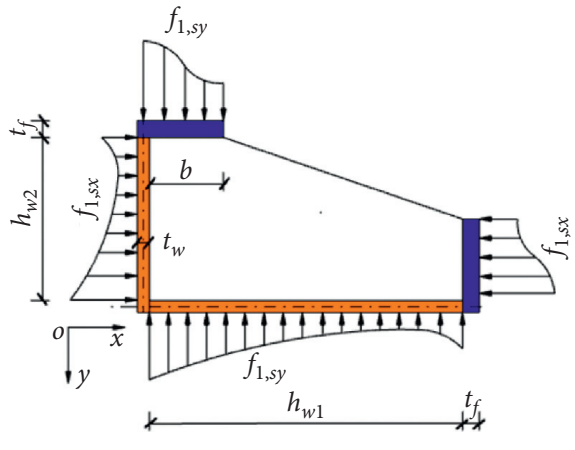

(a)

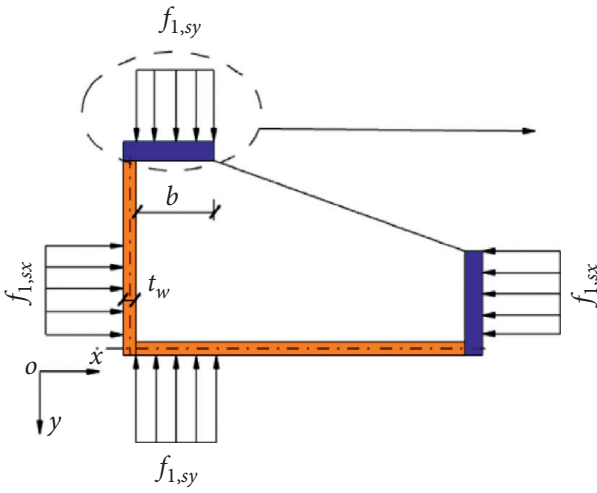

(b)

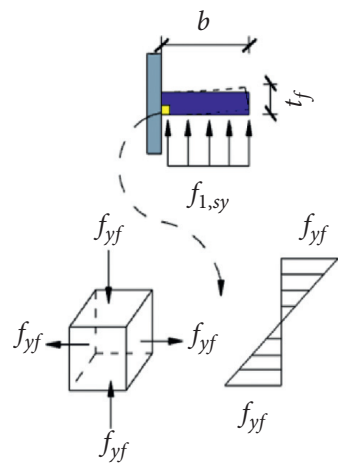

(c)

Figure 11: Distribution of the lateral confining stress: (a) actual confining stress, (b) simplified confining stress, and (c) flange stress state.

According to the simplified confining stress state (Figure 11(b)), the concrete area embedded in the steel profile can be simplified as presented in Figure 12(a). According to Figure 12(b), the concrete area (ABCDE) also can be divided into three regions: the steel unconfined region (BCO), steel uniaxially confined region (ABOG and OCDF), and steel biaxially confined region (GOFE). Furthermore, SRCC-MCS-core columns can be divided as illustrated in Figure 12(c).

Similarly, SRC-core columns with T-shaped and L-shaped steel can be divided as presented in Figure 13.

To consider the uneven distribution of confining stress, the effective confining coefficient $K_{\mathrm{e}}$ for steel profile was also adopted to compute the effective lateral confining stress $f_{\text {le,s }}$ provided by the monosymmetric cross-shaped steel [17]:

$$
K_{e}=\frac{A_{\mathrm{ec}}}{A_{\mathrm{cc}}}
$$

where $A_{\mathrm{ec}}$ is the area of the effectively confined concrete and $A_{\mathrm{cc}}$ is the area of the total confined concrete.

Mirza and Skrabek [36] assumed that the effective area of concrete confined by an H-shaped steel section is the total confined concrete area following the subtraction of the areas of the two parabolas (Figure 14(a)). In this study, the quarter steel profile was simplified as two superimposed $1 / 2$ $\mathrm{H}$-shaped steel sections. The examined effective confined concrete area is illustrated in Figure 14(b). The effective confined concrete area was divided using a simpler process than that used by Zhao et al. [22]; we considered the influence of the cross-shaped steel eccentricity ratio on the strengths of the biaxially confined regions (I and II), as the previously developed analysis model of concrete confined by a cross-shaped steel section [22] is likely unsuitable for monosymmetric cross-shaped steel.

The effective lateral confining stress from the $1 / 2$ $\mathrm{H}$-shaped steel in the $x$ and $y$ directions can be calculated as follows [17]:

$$
\begin{aligned}
& f_{\text {le,sx }}=K_{\text {ex }} f_{l, s}, \\
& f_{\text {le,sy }}=K_{\text {ey }} f_{l, s},
\end{aligned}
$$

where $f_{\mathrm{le}, \mathrm{sx}}$ and $f_{\mathrm{le}, \mathrm{sy}}$ are the effective lateral confining stresses from the steel profile in the $x$ and $y$ directions, respectively.

According to equation (12) and Figure 14(b), the confinement effectiveness coefficients in the $x$ and $y$ directions are as follows:

$$
\begin{aligned}
& K_{\text {ex }}=1-\frac{h_{w 1}}{6 b}, \\
& K_{\text {ey }}=1-\frac{h_{w 2}}{6 b},
\end{aligned}
$$

where $h_{\mathrm{w} 1}$ and $h_{\mathrm{w} 2}$ are the clear lengths of the web in the $x$ and $y$ directions (Figure 14(b)), respectively.

The effective confining stress of the highly confined concrete can be attributed to both the steel profile and stirrups. 


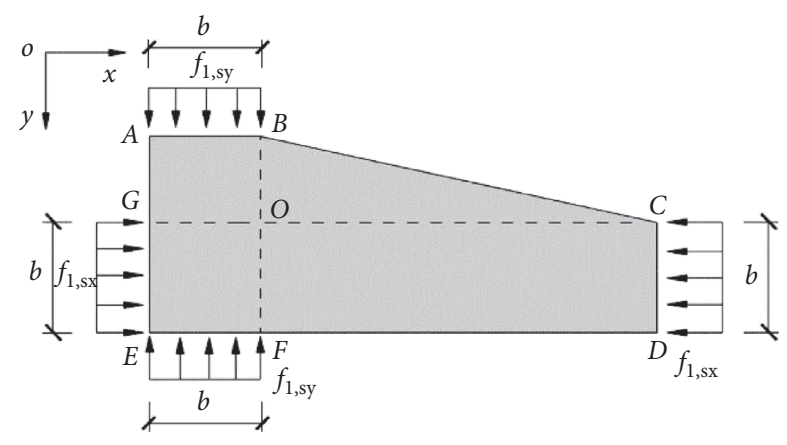

(a)

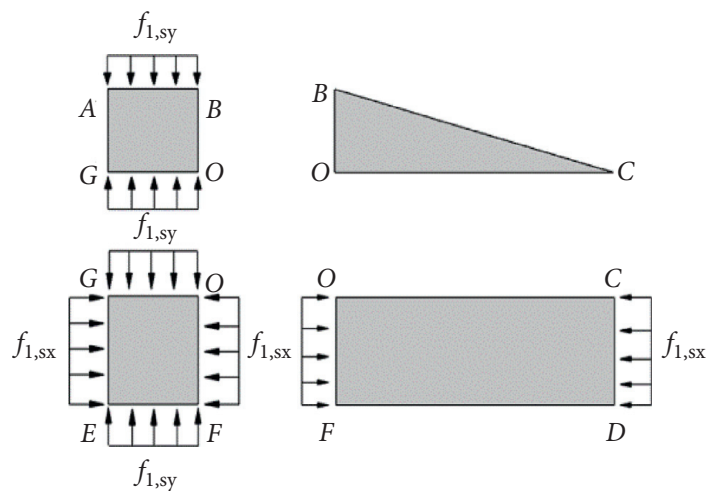

(b)

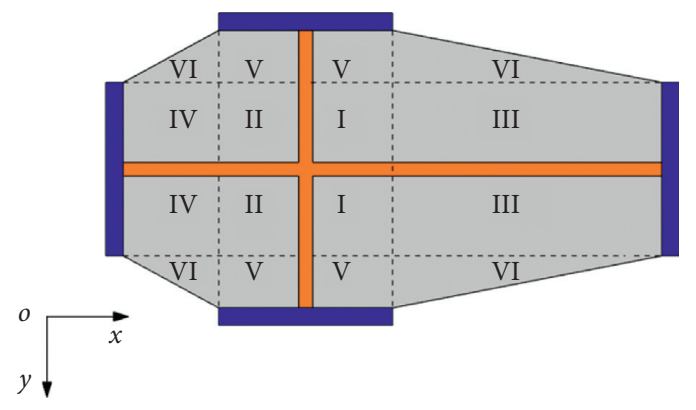

I and II: steel biaxial confined region

III, IV, and V: steel uniaxial confined region

VI: steel unconfined region

(c)

FIGURE 12: Regional partitioning of concrete in the SRCC-MCS-core column: (a) simplified stress state of the confined concrete, (b) simplified stress state of each confined concrete region, and (c) regional partitioning of confined concrete.
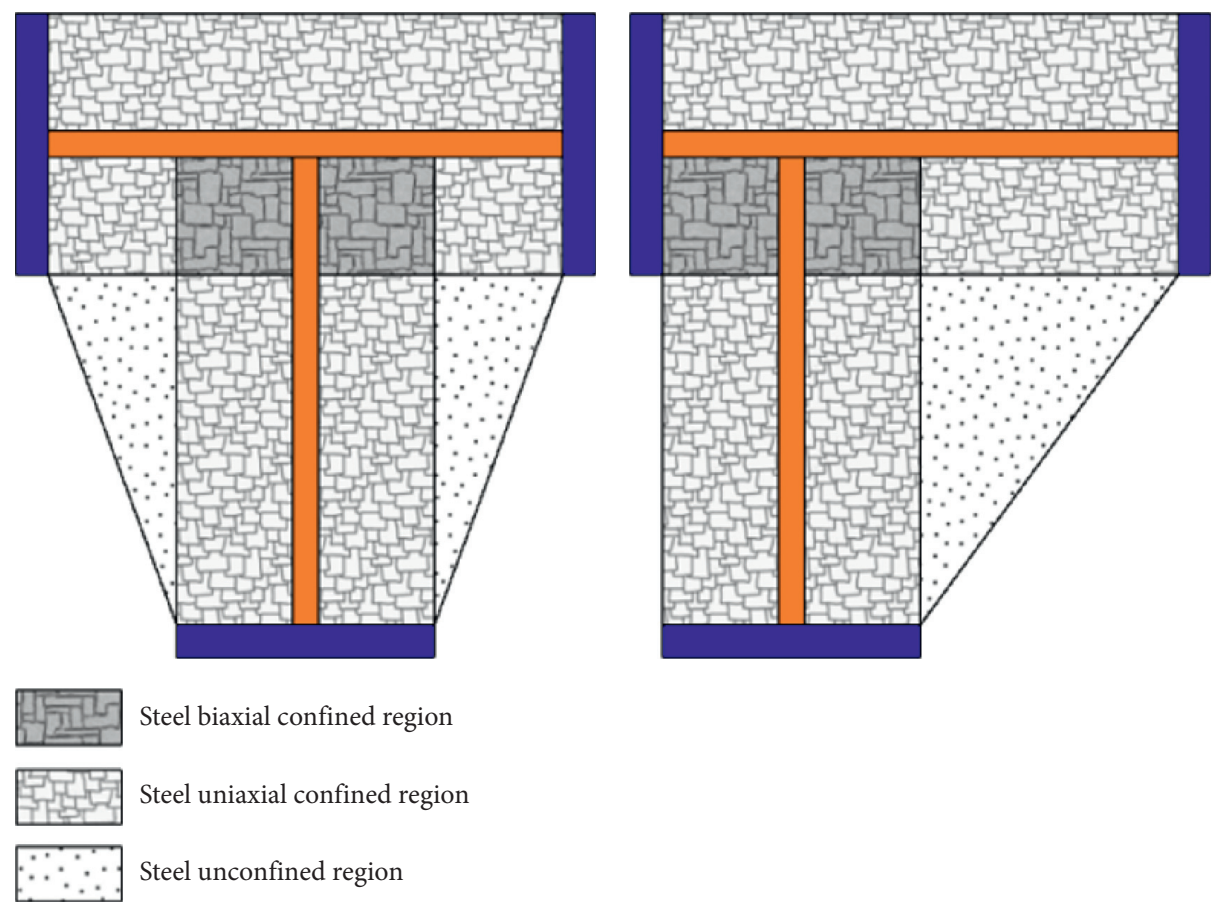

FIGURE 13: Regional partition of the concrete in SRC-core columns with T-shaped and L-shaped steel. 


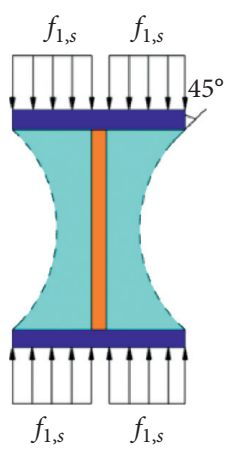

(a)

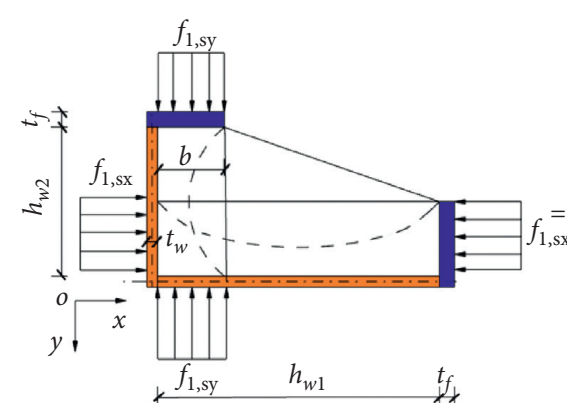

(b)

Figure 14: Effective region of confined concrete for (a) H-shaped steel and (b) monosymmetric cross-shaped steel.

Thus, the effective confining stresses for each of the three confined regions in the $x$ and $y$ directions are as follows [37]:

$$
\begin{aligned}
& f_{\text {le,hx }}=f_{\text {le,px }}+f_{\text {le }, \mathrm{sx}}, \\
& f_{\text {le,hy }}=f_{\text {le,py }}+f_{\text {le }, \mathrm{sy}},
\end{aligned}
$$

where $f_{\text {le,hx }}$ and $f_{\text {le,hy }}$ are the effective lateral confining stresses from both the stirrups and the steel profile in the $x$ and $y$ directions, respectively.

Based on equations (15) and (16), the effective confining stresses of the three confined regions in the $x$ and $y$ directions can be determined by superimposing the effective confining stresses provided by the stirrups and steel profile in the $x$ and $y$ directions (Figure 12(c)). Furthermore, the strengths of the steel biaxially confined regions (I and II) and steel uniaxially confined regions (III-V) can be obtained from Figure 9 [17].

The axial capacity $N_{\mathrm{c}}$ can then be calculated by summing the contributions of all components:

$$
\begin{aligned}
N_{c}= & f_{\mathrm{uc}} A_{\mathrm{uc}}+f_{\mathrm{pc}}\left(A_{\mathrm{pc}}+A_{\mathrm{hc} 6}\right)+f_{\mathrm{hc} 1} A_{\mathrm{hc} 1} \\
& +f_{\mathrm{hc} 2} A_{\mathrm{hc} 2}+f_{\mathrm{hc} 3} A_{\mathrm{hc} 3}+f_{\mathrm{hc} 4} A_{\mathrm{hc} 4} \\
& +f_{\mathrm{hc} 5} A_{\mathrm{hc} 5}+f_{\mathrm{yf}} A_{\mathrm{sf}}+f_{\mathrm{yw}} A_{\mathrm{sw}}+f_{\mathrm{yr}} A_{\mathrm{sr}},
\end{aligned}
$$

where $f_{\mathrm{hc} 1}, f_{\mathrm{hc} 2}, f_{\mathrm{hc} 3}, f_{\mathrm{hc} 4}$, and $f_{\mathrm{hc} 5}$ are the strengths of the highly confined concrete in the respective confined regions shown in Figure 12(c); $A_{\mathrm{hc1}}, A_{\mathrm{hc} 2}, A_{\mathrm{hc} 3}, A_{\mathrm{hc} 4}$, and $A_{\mathrm{hc} 5}$ are the areas of highly confined concrete in the respective confined regions shown in Figure 12(c); $A_{\mathrm{sf}}$ and $A_{\mathrm{sw}}$ are the areas of the steel flange and web, respectively; and $f_{\mathrm{yf}}$ and $f_{\mathrm{yw}}$ are the yield strengths of the flange and web, respectively.

According to the confined stress level in the highly confined concrete region (Figure 12), the order of the strengths of the steel biaxially confined regions (I and II) and steel uniaxially confined regions (III-V) is $f_{\mathrm{hc} 3}<f_{\mathrm{hc} 4}<f_{\mathrm{hc5}}<f_{\mathrm{hcl}}<f_{\mathrm{hc2}}$. To simplify the calculation for practical applications, $f_{\mathrm{hc} 3}$ is adopted to substitute the strengths of the steel biaxially confined regions (I and II) and steel uniaxially confined regions (IV and V) in equation (17). Thus, equation (17) is simplified as follows:

$$
\begin{aligned}
N_{c}= & f_{\mathrm{uc}} A_{\mathrm{uc}}+f_{\mathrm{pc}}\left(A_{\mathrm{pc}}+A_{\mathrm{hc} 6}\right)+f_{\mathrm{hc} 3}\left(A_{\mathrm{hcl}}+A_{\mathrm{hc} 2}+A_{\mathrm{hc} 3}\right. \\
& \left.+A_{\mathrm{hc} 4}+A_{\mathrm{hc} 5}\right)+f_{\mathrm{yf}} A_{\mathrm{sf}}+f_{\mathrm{yw}} A_{\mathrm{sw}}+f_{\mathrm{yr}} A_{\mathrm{sr}} .
\end{aligned}
$$

4.4. Verification of Established Method. Three representative design codes were employed to calculate the axial capacity of all the specimens: ACI 138-14 [23], EN 1994-1-1 [24], and JGJ 138-2016 [25]. These codes, respectively, define axial capacity as follows:

$$
\begin{aligned}
N_{\mathrm{ACI}} & =0.85\left[0.85 f_{\mathrm{co}}\left(A_{c}-A_{a}-A_{\mathrm{sr}}\right)+f_{\mathrm{ya}} A_{a}+f_{\mathrm{yr}} A_{\mathrm{sr}}\right], \\
N_{\mathrm{EC} 4} & =0.85 f_{\mathrm{co}} A_{c}+f_{\mathrm{ya}} A_{a}+f_{\mathrm{yr}} A_{\mathrm{sr}}, \\
N_{\mathrm{JGJ}} & =0.9\left(f_{c} A_{c}+f_{\mathrm{ya}} A_{a}+f_{\mathrm{yr}} A_{\mathrm{sr}}\right),
\end{aligned}
$$

where $f_{c}$ is the axial compression strength of concrete $\left(f_{\mathrm{c}}=0.67 f_{\mathrm{cu}}\right)$ [38]. Figures 15(a)-15(c) compare the results obtained using the three codes with the experimental results. All three codes appeared to underestimate the axial capacity of all specimens, and neither considered the implications of the cross-shaped steel eccentricity ratio on the axial capacity of the specimens because the lateral confining effect of the hoops and the steel profile were neglected.

Figures 15(d)-15(e) compare the axial capacities calculated using equations (17) and (18) with the experimental results for all specimens. The axial capacities of the SRCCMCS specimens calculated using equation (18) were more conservative than those computed using equation (17). However, the errors in the results obtained using either method were less than $10 \%$, which indicated that both methods can be used to compute the axial capacity of SRCCMCSs.

Furthermore, 10 SRCC-CSs [39] were assessed to validate the two proposed calculation methods, and the results are shown in Figure 16. It was found that the axial capacities computed using the proposed methods were consistent with the test results. Thus, the applicability of the established method was confirmed. 


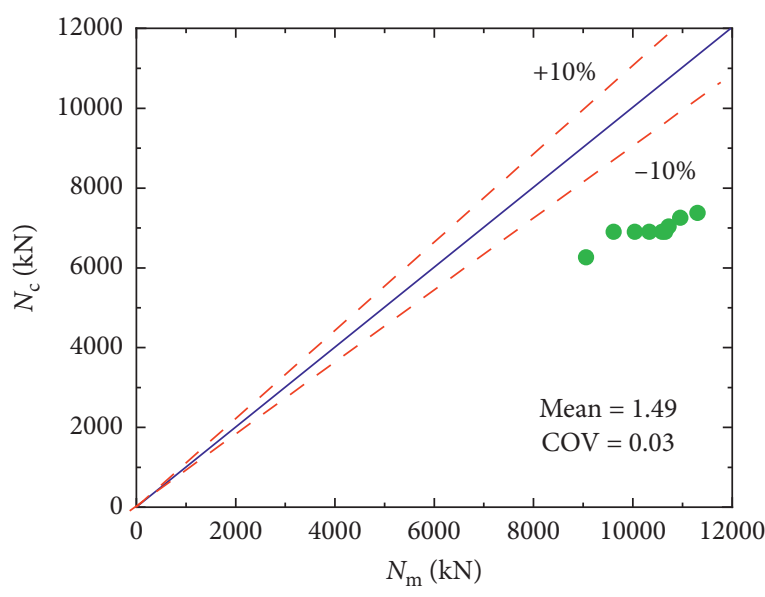

- Test data

(a)

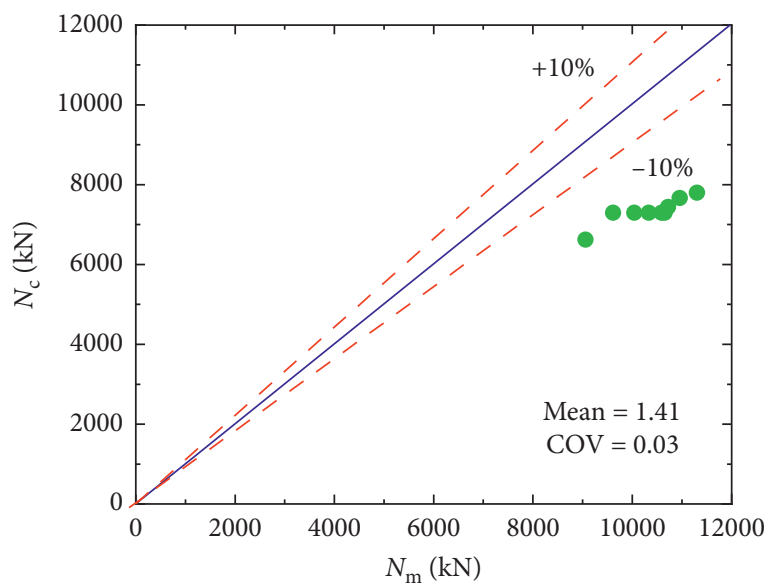

- Test data

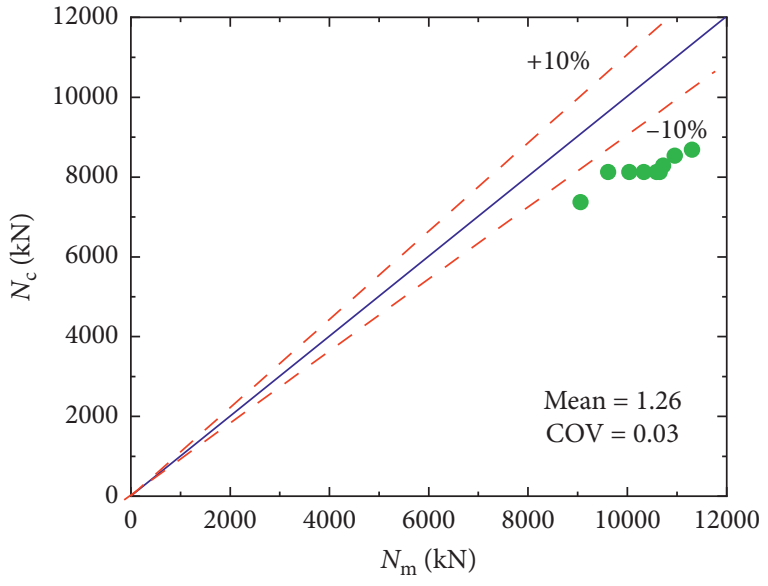

Test data

(b)

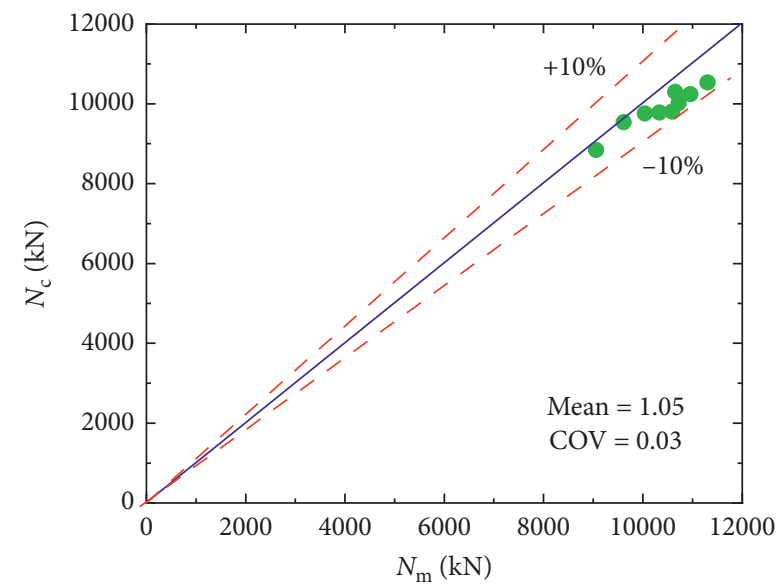

- Test data

(c)

(d)

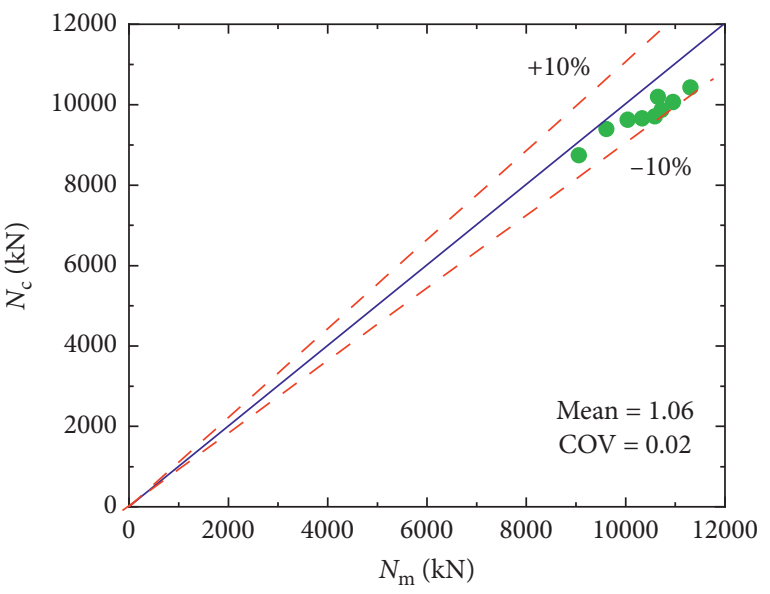

- Test data

(e)

FIGURE 15: Comparison of test results with results predicted using (a) ACI 138-14 [23], (b) EN 1994-1-1 [24], (c) JGJ 138-2016 [25], (d) the proposed method, and (e) the simplified method. 


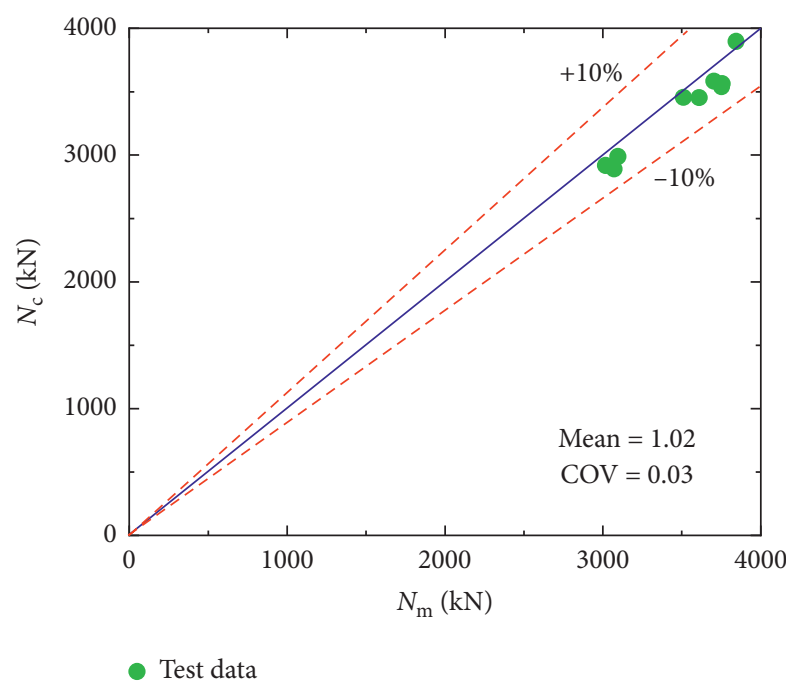

(a)

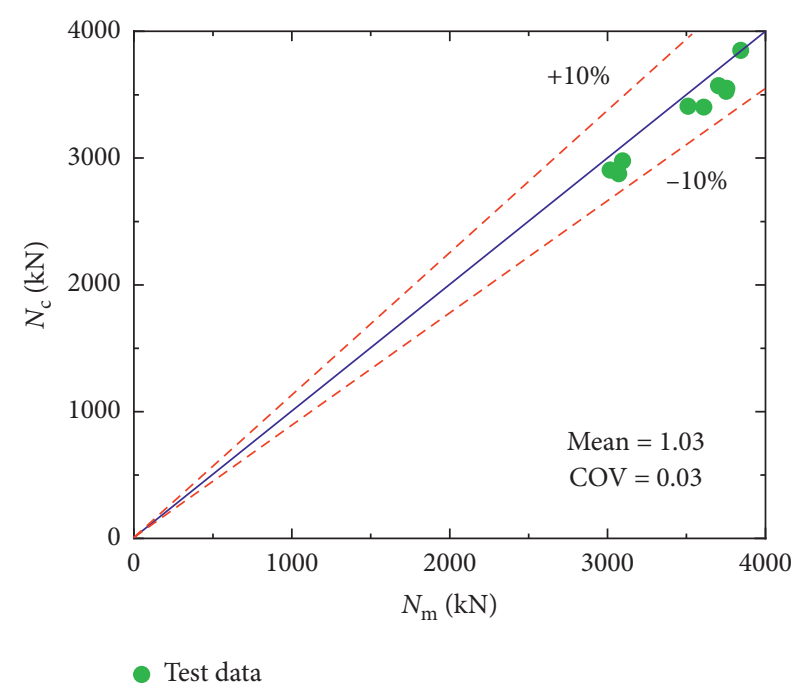

(b)

FIGURE 16: Comparison of experimental results in the literature [39] with results calculated using the (a) proposed method and (b) simplified method.

\section{Conclusions}

This paper presented an experimental investigation of the axial performance of SRCC-MCSs. The influence of crossshaped steel eccentricity ratio, concrete strength, steel ratio, and stirrup spacing on the failure modes, load-strain curves, and load-displacement curves of nine specimens was analysed. Two methods for computing the axial capacity of the SRCC-MCS were then proposed. The key conclusions can be summarised as follows:

(1) Under pure compression, the failure of the SRCC-CS specimen was relatively uniform, whereas the damage locations on the SRCC-MCS specimens were away from the eccentric $\mathrm{H}$-shaped steel as the lateral confining stress provided by the monosymmetric cross-shaped steel was unsymmetrical.

(2) For the SRCC-MCS specimens, the strain in the steel flange farthest from the centroid of the eccentric $\mathrm{H}$-shaped steel was larger than that nearer the eccentric H-shaped steel centroid at the peak load. The same result was observed for the strain in the stirrups. However, the steel profile and stirrups reached their yielding strengths prior to the peak load, indicating that their strengths were fully mobilised.

(3) The axial capacity and ductility of the specimens decreased with increasing cross-shaped steel eccentricity ratio. Increasing the concrete strength markedly enhanced the axial capacities of the specimens but significantly reduced their ductilities. The axial capacity and ductility increased as the steel ratio increased and the stirrup spacing decreased, which can be attributed to the confining action of the steel profile and stirrups.

(4) A method for calculating the axial capacity of SRCCMCS was established by accounting for the action of the confining stress of the steel profile and stirrups on the concrete. A simplified calculation method was also proposed for practical application. The axial capacities computed using the two methods were compared with those computed using the methods specified in three existing codes and were validated against test results. The axial capacities calculated using the code-specified methods were excessively conservative, while the results obtained using the two proposed methods agreed well with the test results. Furthermore, the two proposed methods were used to calculate the axial capacities of SRCC-CS specimens evaluated in a previous study, and the computed and experimental results were consistent with each other.

Owing to the limited number of parameters used to investigate the axial performance of the SRCC-MCSs, the axial performance of SRCC-MCS with different parameters, such as slenderness ratio, steel profile strength, or longitudinal reinforcement ratio, should be tested further. Meanwhile, the structural performances of SRCC-MCS under different loading conditions, including pure bending, eccentric compression, and cyclic loading, must be investigated in detail.

\section{Data Availability}

The data used to support the findings of this study are available from the corresponding author upon request. 


\section{Conflicts of Interest}

The authors declare that they have no conflicts of interest.

\section{Acknowledgments}

The financial supports were provided by the Natural Science Foundation of Shaanxi Province (Grant no. 2019SF-239).

\section{References}

[1] P. Lacki, A. Derlatka, and P. Kasza, "Comparison of steelconcrete composite column and steel column," Composite Structures, vol. 202, pp. 82-88, 2018.

[2] C. Hui, Y. Zhu, W. Cao, and Y. Wang, "Seismic experiment and analysis of rectangular bottom strengthened steelconcrete composite columns," Steel and Composite Structures, vol. 20, no. 3, pp. 599-621, 2016.

[3] M. M. A. Mostafa, T. Wu, X. Liu, and B. Fu, "The composite steel reinforced concrete column under axial and seismic loads: a review," International Journal of Steel Structures, vol. 19, no. 6, pp. 1969-1987, 2019.

[4] C. Xu, L. Zeng, Q. Zhou, X. Tu, and Y. Wu, "Cyclic performance of concrete-encased composite columns with T-shaped steel sections," International Journal of Civil Engineering, vol. 13, no. 4, pp. 455-467, 2015.

[5] C.-C. Chen, J.-M. Li, and C. C. Weng, "Experimental behaviour and strength of concrete-encased composite beamcolumns with T-shaped steel section under cyclic loading," Journal of Constructional Steel Research, vol. 61, no. 7, pp. 863-881, 2005.

[6] L. Zeng, X. Tu, C. X. Xu, S. S. Zheng, and Y. Y. Wu, "Experimental study on seismic behavior of steel reinforced concrete column with unsymmetrical steel cross-sections," Journal of Building Structures, vol. 34, no. 3, pp. 141-151, 2013, in Chinese.

[7] B. L. Lai, J. Y. R. Liew, and M. X. Xiong, "Experimental study on high strength concrete encased steel composite short columns," Construction and Building Materials, vol. 228, Article ID 116640, 2019.

[8] B. Wu, S. M. Jian, and X. Y. Zhao, "Structural behavior of steel-concrete partially encased composite columns containing demolished concrete lumps under axial compression," Engineering Structures, vol. 197, Article ID 109383, 2019.

[9] C.-S. Kim, H.-G. Park, K.-S. Chung, and I.-R. Choi, "Eccentric axial load testing for concrete-encased steel columns using $800 \mathrm{MPa}$ steel and $100 \mathrm{MPa}$ concrete," Journal of Structural Engineering, vol. 138, no. 8, pp. 1019-1031, 2012.

[10] C. S. Kim, H. G. Park, K. S. Chung, and I. R. Choi, "Eccentric axial load capacity of high-strength steel-concrete composite columns of various sectional shapes," Journal of Structural Engineering, vol. 140, no. 4, Article ID 04013091, 2014.

[11] Y. Yang, Y. Xue, Y. Yu, and F. Gao, "Experimental study on seismic performance of partially precast steel reinforced concrete columns," Engineering Structures, vol. 175, pp. 63$75,2018$.

[12] C. H. Chen, C. K. Wang, and H. Z. Sun, "Experimental study on seismic behavior of full encased steel-concrete composite columns," Journal of Structural Engineering, vol. 140, no. 6, Article ID 04014024, 2014.

[13] K. Roik and R. Bergmann, "Design method for composite columns with unsymmetrical cross-sections," Journal of Constructional Steel Research, vol. 15, no. 1-2, pp. 153-168, 1990.
[14] Y. Nishimura, S. Tsutsui, and N. Baba, "Flexural behavior of steel reinforced concrete columns with T-shaped steel," in Proceedings of the 13th World Conference on Earthquake Engineering, Article ID 1338, Vancouver, Canada, August 2004.

[15] L. Bing, R. Park, and H. Tanaka, "Stress-strain behavior of high-strength concrete confined by ultra-high- and normalstrength transverse reinforcements," ACI Structural Journal, vol. 98, no. 3, pp. 395-406, 2001.

[16] S. A. Sheikh and S. M. Uzumeri, "Analytical model for concrete confinement in tied columns," Journal of Structural Division, vol. 108, no. 12, pp. 2703-2722, 1982.

[17] J. B. Mander, M. J. N. Priestley, and R. Park, "Theoretical stress-strain model for confined concrete," Journal of Structural Engineering, vol. 114, no. 8, pp. 1804-1826, 1988.

[18] M. Saatcioglu and S. R. Razvi, "Strength and ductility of confined concrete," Journal of Structural Engineering, vol. 118, no. 6, pp. 1590-1607, 1992.

[19] S. Chen and P. Wu, "Analytical model for predicting axial compressive behavior of steel reinforced concrete column," Journal of Constructional Steel Research, vol. 128, pp. 649-660, 2017.

[20] C.-C. Chen and N.-J. Lin, "Analytical model for predicting axial capacity and behavior of concrete encased steel composite stub columns," Journal of Constructional Steel Research, vol. 62, no. 5, pp. 424-433, 2006.

[21] Y. Yang, Y. Chen, and S. Q. Feng, "Study on behavior of partially prefabricated steel reinforced concrete stub columns under axial compression," Engineering Structures, vol. 199, Article ID 109630, 2019.

[22] X. Z. Zhao and F. P. Wen, "Theoretical study on confinement mechanism and stress-strain for steel confined concrete in SRC columns," Engineering Mechanics, vol. 35, no. 5, pp. 36-46, 2018, in Chinese.

[23] ACI 318-14, Building Code Requirements for Structural Concrete and Commentary, American Concrete Institute, Farmington Hills, MI, USA, 2014.

[24] EN 1994-1-1, Eurocode 4, Design of Composite Steel and Concrete Structures-Part 1-1, General Rules and Rules for Buildings, European Committee for Standardization, Brussels, Belgium, 2004.

[25] JGJ 138-2016, Code For Design of Composite Structures, Ministry of Housing and Urban-Rural Development of the People's Republic of China, Beijing, China, 2016, in Chinese.

[26] L. L. Sun, Q. J. Ma, F. Han et al., "Experimental investigation on axial compression behavior of steel reinforced concrete columns with welded stirrups," Engineering Structures, vol. 208, Article ID 109924, 2020.

[27] JGJ 3-2010, Technical Specification for Concrete Structures of Tall Building, Ministry of Housing and Urban-Rural Development of the People's Republic of China, Beijing, China, 2010, in Chinese.

[28] GB/T 50081-2010, Standard For Test Method of Mechanical Properties on Ordinary Concrete, Chinese Architecture \& Building Press, Beijing, China, 2010, in Chinese.

[29] GB/T 228.1-2010, Metallic Materials - Tensile Testing - Part 1: Method Of Test at Room Temperature, China Standards Press, Beijing, China, 2010, in Chinese.

[30] S. Tokgoz and C. Dundar, "Experimental tests on biaxially loaded concrete-encased composite columns," Steel and Composite Structures, vol. 8, no. 5, pp. 423-438, 2008.

[31] Q. Xiong, Z. Chen, W. Zhang, Y. Du, T. Zhou, and J. Kang, "Compressive behaviour and design of L-shaped columns 
fabricated using concrete-filled steel tubes," Engineering Structures, vol. 152, pp. 758-770, 2017.

[32] Y. Liu, Z. X. Guo, P. H. Xu, and L. P. Jia, "Experimental study on axial compression behavior of core steel reinforced concrete columns," Journal of Building Structures, vol. 36, no. 4, pp. 68-74, 2015, in Chinese.

[33] K. Karimi, M. J. Tait, and W. W. El-Dakhakhni, “Testing and modeling of a novel FRP-encased steel-concrete composite column," Composite Structures, vol. 93, no. 5, pp. 1463-1473, 2011.

[34] X. Z. Zhao, H. Qin, and Y. Y. Chen, "Experimental study on constitutive model of steel confined concrete in SRC columns with cruciform steel section," Journal of Building Structures, vol. 35, no. 4, pp. 268-279, 2014, in Chinese.

[35] J. Liu, S. J. Foster, and M. M. Attard, "Strength of tied highstrength concrete columns loaded in concentric compression," ACI Structural Journal, vol. 97, no. 1, pp. 149-156, 2000.

[36] S. A. Mirza and B. W. Skrabek, "Statistical analysis of slender composite beam-column strength," Journal of Structural Engineering, vol. 118, no. 5, pp. 1312-1332, 1992.

[37] S. M. El-Tawil and G. G. Deierlein, Fiber Element Analysis of Composite Beam-Column Cross-Sections, Cornell University, Ithaca, NY, USA, 1996.

[38] Y. F. Xiao, X. M. Bie, X. Song, J. C. Zhang, and G. F. Du, "Performance of composite L-shaped CFST columns with inner I-shaped steel under axial compression," Journal of Construction Steel Research, vol. 170, Article ID 106138, 2020.

[39] K. C. Tsai, Y. Lien, and C. C. Chen, "Behavior of axially loaded steel reinforced concrete columns," Journal of the Chinese Institute of Civil Hydraulic Engineering, vol. 8, no. 4, pp. 535-545, 1996, in Chinese. 